\title{
The Rac-GEF Tiam1 Promotes Dendrite and Synapse Stabilization of Dentate Granule Cells and Restricts Hippocampal-Dependent Memory Functions
}

\author{
Jinxuan Cheng, ${ }^{1,2}$ Federico Scala, ${ }^{2}{ }^{\circledR}$ Francisco A. Blanco, ${ }^{2,3}{ }^{\circledR}$ Sanyong Niu, ${ }^{2}{ }^{\circledR}$ Karen Firozi, ${ }^{2}$ Laura Keehan, ${ }^{4}$ \\ Shalaka Mulherkar, ${ }^{2}$ Emmanouil Froudarakis, ${ }^{2}$ Lingyong Li, ${ }^{2}$ Joseph G. Duman, ${ }^{2}$ Xiaolong Jiang, ${ }^{2,5}$ and \\ Kimberley F. Tolias ${ }^{1,2}$ \\ ${ }^{1}$ Verna and Marrs McLean Department of Biochemistry and Molecular Biology, Baylor College of Medicine, Houston, Texas 77030, ${ }^{2}$ Department of \\ Neuroscience, Baylor College of Medicine, Houston, Texas 77030, ${ }^{3}$ Integrative Molecular and Biomedical Science Graduate Program, Baylor College \\ of Medicine, Houston, Texas 77030, ${ }^{4}$ Department of Biosciences, Rice University, Houston, Texas 77005, and ${ }^{5}$ Jan and Dan Duncan Neurological \\ Research Institute at Texas Children's Hospital, Houston, Texas 77030
}

The dentate gyrus (DG) controls information flow into the hippocampus and is critical for learning, memory, pattern separation, and spatial coding, while DG dysfunction is associated with neuropsychiatric disorders. Despite its importance, the molecular mechanisms regulating DG neural circuit assembly and function remain unclear. Here, we identify the Rac-GEF Tiam1 as an important regulator of DG development and associated memory processes. In the hippocampus, Tiam1 is predominantly expressed in the DG throughout life. Global deletion of Tiam1 in male mice results in DG granule cells with simplified dendritic arbors, reduced dendritic spine density, and diminished excitatory synaptic transmission. Notably, DG granule cell dendrites and synapses develop normally in Tiam1 KO mice, resembling WT mice at postnatal day 21 (P21), but fail to stabilize, leading to dendrite and synapse loss by P42. These results indicate that Tiam1 promotes DG granule cell dendrite and synapse stabilization late in development. Tiam1 loss also increases the survival, but not the production, of adultborn DG granule cells, possibly because of greater circuit integration as a result of decreased competition with mature granule cells for synaptic inputs. Strikingly, both male and female mice lacking Tiam1 exhibit enhanced contextual fear memory and context discrimination. Together, these results suggest that Tiam1 is a key regulator of DG granule cell stabilization and function within hippocampal circuits. Moreover, based on the enhanced memory phenotype of Tiam1 KO mice, Tiam1 may be a potential target for the treatment of disorders involving memory impairments.

Key words: Adult neurogenesis; Dentate gyrus; Dendrites; Learning and memory; Rho GTPase; Synapse development

Significance Statement

The dentate gyrus (DG) is important for learning, memory, pattern separation, and spatial navigation, and its dysfunction is associated with neuropsychiatric disorders. However, the molecular mechanisms controlling DG formation and function remain elusive. By characterizing mice lacking the Rac-GEF Tiam1, we demonstrate that Tiam1 promotes the stabilization of DG granule cell dendritic arbors, spines, and synapses, whereas it restricts the survival of adult-born DG granule cells, which compete with mature granule cells for synaptic integration. Notably, mice lacking Tiam1 also exhibit enhanced contextual fear memory and context discrimination. These findings establish Tiaml as an essential regulator of DG granule cell development, and identify it as a possible therapeutic target for memory enhancement.

Received Nov. 16, 2017; revised Nov. 25, 2020; accepted Dec. 1, 2020.

Author contributions: J.C., F.S., F.A.B., S.N., K.F., X.J., and K.F.T. designed research; J.C., F.S., F.A.B., S.N., K.F., L.K., S.M., L.L., X.J., and K.F.T. performed research; J.C., F.S., F.A.B., L.K., S.M., E.F., L.L., J.G.D., X.J., and K.F.T. analyzed data; J.C. and K.F.T. wrote the paper; S.N. contributed unpublished reagents/analytic tools; J.G.D. and K.F.T. edited the paper.

This work was supported by National Institutes of Health Grants NS062829, MH109511, and MH103108 to K.F.T., Grant T32 GM008231 to F.A.B., and the Mission Connect-TIRR Foundation to K.F. T. We also received technical assistance and resources from the BCM Neuropathology and Behavioral
IDDRC Cores (supported by National Institutes of Health Grant U54 HD083092). We thank Corinne Spencer, Mauro Costa-Mattioli, Surabi Veeraragavan, and Yi-Ting Cheng and other K.F.T. laboratory members for technical advice and support.

The authors declare no competing financial interests.

Correspondence should be addressed to Kimberley F. Tolias at tolias@bcm.edu.

https://doi.org/10.1523/JNEUROSCI.3271-17.2020

Copyright $\odot 2021$ the authors 


\section{Introduction}

The hippocampus mediates fundamental brain functions, including learning, episodic memory formation, spatial coding, and mood regulation (Leuner and Gould, 2010). The main gateway for information flow into the hippocampus, the dentate gyrus (DG), plays an integral role in these processes. The DG relays excitatory input from the entorhinal cortex to area CA3 of the hippocampus (Lopez-Rojas and Kreutz, 2016). The DG also mediates pattern separation, which differentiates related memories by transforming similar input firing patterns into distinct output firing patterns (Kheirbek et al., 2012a). This is possible because the DG possesses a relatively large number of principal neurons (i.e., DG granule cells) that are sparsely active, allowing for divergence in information flow (Kheirbek et al., 2012a). The DG is also one of two known brain regions that generate new neurons throughout life (i.e., adult neurogenesis), which facilitates memory and mood regulation (Ming and Song, 2011; Gonçalves et al., 2016). Conversely, DG dysfunction is associated with neuropsychiatric disorders characterized by memory and mood dysregulation, including Alzheimer's disease, post-traumatic stress disorder, schizophrenia, and depression, and normalizing or enhancing DG function improves symptoms of these disorders (Tamminga et al., 2010; Shin et al., 2013; Miller and Hen, 2015; Gonçalves et al., 2016; Hollands et al., 2016; Berger et al., 2020). Thus, it is imperative to better understand the molecular mechanisms that control DG formation and function.

A critical aspect of DG development is the establishment of DG granule cell excitatory synapses, which mediate information flow and storage in the DG (Amaral et al., 2007; Jonas and Lisman, 2014). Proper excitatory synaptic connectivity requires the precise growth and stabilization of DG granule cell dendritic arbors and spines, the actin-rich postsynaptic compartments of most excitatory synapses (Zhao et al., 2006; Rahimi and Claiborne, 2007). The development of dendrites and spiny synapses is orchestrated by the small Rho-family GTPase Rac1 (Tolias et al., 2011; Duman et al., 2015). Like most GTPases, Racl cycles between an active GTP-bound state and an inactive GDP-bound state (Tolias et al., 2011). Upon activation, Rac1 interacts with downstream effectors, stimulating signaling pathways that control cytoskeletal remodeling, membrane trafficking, and gene expression (Bishop and Hall, 2000). In neurons, Rac1 signaling promotes dendritic arborization, spine growth, and synapse development and plasticity (Newey et al., 2005). To function properly, Racl requires precise spatiotemporal regulation, which is provided by a wide range of activators (guanine nucleotide exchange factors [GEFs]) and inhibitors (GTPaseactivating proteins [GAPs]) (Tolias et al., 2011; Duman et al., 2015). Previously, using dissociated rat hippocampal neurons, we identified the Rac-GEF Tiam1 as a critical regulator of dendrite, spine, and synapse development (Tolias et al., 2005). Tiam1 controls spine morphogenesis and synapse development by coupling synaptic receptors to Rac1-dependent actin cytoskeletal remodeling (Tolias et al., 2005, 2007; Zhang and Macara, 2006; Lai et al., 2012; Duman et al., 2013; Um et al., 2014). The ability of Tiam 1 to precisely regulate Racl signaling and excitatory synapse development also depends on its cooperation with a Tiam1-associated Rac-GAP, Bcr (Narayanan et al., 2013; Um et al., 2014). In the brain, Tiam1 is particularly highly expressed throughout life in the DG (Ehler et al., 1997; Rao et al., 2019). However, since most studies investigating Tiaml function have been performed using dissociated hippocampal neurons in culture, or more recently in cultured hippocampal slices (Rao et al., 2019), the in vivo roles of Tiam 1 in the mammalian brain remain unclear. This knowledge gap is unfortunate, given that altered Tiam1 expression is associated with a variety of brain disorders including Down syndrome, major depressive disorder, Rett syndrome, and chronic cocaine exposure (Aston et al., 2005; Chahrour et al., 2008; Ahmed et al., 2013; Chandra et al., 2013; Vacca et al., 2016).

To determine Tiam1's role in the brain, we generated Tiam1 $\mathrm{KO}$ mice. Characterization of these mice revealed that Tiam 1 is essential for the proper establishment of hippocampal circuits by promoting the maturation and stabilization of DG granule cell dendritic arbors, spines, and excitatory synapses and by restricting the survival of adult-born DG granule neurons. We also discovered that Tiam1 plays an important role in regulating DGrelated behaviors, as Tiam $1 \mathrm{KO}$ mice display enhanced contextual fear learning and spatial discrimination. Notably, these behavioral phenotypes are markedly different from mice lacking other synaptic Rac-GEFs, including Kalirin-7 and $\alpha$ PIX/Arhgef6 (Ma et al., 2008; Cahill et al., 2009; Kiraly et al., 2011; Ramakers et al., 2012; Miller et al., 2013), highlighting Tiam1's unique role in the brain. Our results establish Tiam1 as a critical regulator of DG development and behavior, and identify it as a possible therapeutic target for the treatment of brain disorders involving memory impairments.

\section{Material and Methods}

Animals

Tiam $1^{\text {flox/flox }}$ mice were generated by inserting two loxP sites into a region of the targeted Tiam 1 gene flanking exon 5. An internal Frt-flanked neomycin was also introduced into the Tiam 1 gene as a selection marker, which was subsequently removed by crossing the Tiam $1^{f l f l}$ mice to mice expressing flippase. For global embryonic deletion of Tiam1, Tiam $1^{\text {fl/fl }}$ mice were crossed with Ella-Cre transgenic mice. The resulting Tiam $1^{+/-}$; EIIa-Cre mice were crossed with 129 S6/SvEv mice to remove Cre. Tiam $1^{+/-}$mice were then interbred to generate Tiam $1^{-/-}$KO mice and Tiam $1^{+/+}$WT littermates for use in experiments. For detailed spine analyses, Tiam $1 \mathrm{KO}$ mice were crossed with Thy1-YFP (line $\mathrm{H}$ ) transgenic mice (Feng et al., 2000) and then interbred to generate Tiam1 ${ }^{-/-}$; Thy1YFP (KO;YFP) and Tiam $1^{+/+}$; Thy1-YFP (WT;YFP) mice. All experiments used age-matched male and female mice, except for electrophysiology and neuron morphology experiments, which used solely age-matched male mice. Adult mice were used for all experiments unless otherwise indicated. Mice were group housed under standard $12 \mathrm{~h}$ light cycle. Genotyping of Tiam 1 mice was determined by PCR from tail DNA using the following primers: P1: ACGTGTGTTAATT AGCCAGGTTTGATGG; P2: GATCCACTAGTTCTAGA GCGGCCGAA; and P3: CTACCCGGAGGAAGTGGAA GCACTACT. Long-Evans timed-pregnant rats were purchased from Envigo (Harlan).

\section{Ethics statement}

All procedures involving the handling of experimental animals were conducted in strict accordance with the National Institutes of Health guidelines and were approved by the Baylor College of Medicine Institutional Animal Care and Use Committee. Every effort was made to minimize animal suffering.

\section{Antibodies and reagents}

The following antibodies were purchased and used according to their datasheets: anti-Tiam1 (sc-872, Santa Cruz Biotechnology); 
anti-GAPDH (sc-32 233, sc-25 778, Santa Cruz Biotechnology); anti-BrdU (OBT0030G, Accurate Chemical); anti-doublecortin (DCX) (ab18723, Abcam); and anti-NeuN (MAB377, Millipore). We used goat anti-rabbit or anti-mouse HRP-conjugated secondary antibodies (Jackson ImmunoResearch Laboratories) for Western blotting and AlexaFluor-488- or -555-conjugated secondary antibodies (Thermo Fisher Scientific) for immunocytochemistry.

\section{Western blot analysis}

The hippocampi of mice were collected and homogenized in RIPA lysis buffer containing $150 \mathrm{~mm} \mathrm{NaCl}, 1 \% \mathrm{NP}-40,0.5 \%$ deoxycholic acid, 0.1\% SDS, $50 \mathrm{~mm}$ Tris, $\mathrm{pH}$ 8.0, 1 mм EDTA, $1 \mathrm{~mm}$ DTT, $1 \mathrm{~mm} \mathrm{Na}_{3} \mathrm{VO}_{4}, 10 \mathrm{~mm} \mathrm{NaF}, 10 \mathrm{~mm} \beta$-glycerol phosphate, and protease inhibitors (complete tablets, Roche Diagnostic). Protein concentrations were determined using the Pierce BCA protein assay kit (Thermo Fisher Scientific). Protein lysates were separated on SDS-PAGE gels and wet transferred to PVDF membranes. The membranes were blocked with $3 \%$ BSA in $1 \times$ Tris-buffered saline with Tween 20 for $1 \mathrm{~h}$ at room temperature, incubated with primary antibody overnight at $4^{\circ} \mathrm{C}$, and then incubated with HRP-conjugated secondary antibody for $1 \mathrm{~h}$ at room temperature. Western blots were visualized using enhanced chemiluminescence on the Odyssey imaging systems (LI-COR Biosciences) and quantified using ImageJ software. Quantification of the Western blots shows the relative density presented as the ratio of protein over GAPDH.

\section{Immunohistochemistry}

Brains were collected from mice transcardially perfused with $4 \%$ PFA. These brains were cryoprotected in 30\% sucrose after postfixing in $4 \% \mathrm{PFA}$ at $4^{\circ} \mathrm{C}$ overnight. Free-floating brain sections (30 $\mu \mathrm{m}$ thick) were collected using cryosectioning and incubated in antigen retrieval solution (Vector Laboratories) at $80^{\circ} \mathrm{C}$ for $40 \mathrm{~min}$ and then blocking solution (3\% BSA, 10\% goat serum, and $0.1 \%$ Triton X-100 in PBS) at room temperature for $1 \mathrm{~h}$. After blocking, sections were incubated in primary antibody at $4^{\circ} \mathrm{C}$ for 24-36 h, secondary antibody at room temperature for 2 $\mathrm{h}$, and then mounted in the Vectashield antifade mounting medium with DAPI (Vector Laboratories). For BrdU staining, brain sections were treated with $2 \mathrm{~N} \mathrm{HCl}$ at $37^{\circ} \mathrm{C}$ for $25 \mathrm{~min}$ before blocking. For H\&E staining, brain sections were incubated in xylene and dehydrated in $100 \%, 90 \%$, and $80 \%$ ethanol, and then stained with Mayer's H\&E solution.

\section{Electrophysiology}

Hippocampal slice preparations were performed as previously described (Jiang et al., 2015; Cadwell et al., 2016). Briefly, mice were deeply anesthetized using $3 \%$ isoflurane. After decapitation, the brain was removed and placed into cold $\left(0^{\circ} \mathrm{C}-4^{\circ} \mathrm{C}\right)$ oxygenated NMDG solution containing $93 \mathrm{~mm} \mathrm{NMDG}, 93 \mathrm{~mm} \mathrm{HCl,} 2.5$ mм KCl, $1.2 \mathrm{~mm} \mathrm{NaH}_{2} \mathrm{PO}_{4}, 30 \mathrm{~mm} \mathrm{NaHCO}, 20$ mм HEPES, 25 $\mathrm{mm}$ glucose, $5 \mathrm{~mm}$ sodium ascorbate, $2 \mathrm{~mm}$ thiourea, $3 \mathrm{~mm}$ sodium pyruvate, $10 \mathrm{mM} \mathrm{MgSO}_{4}$, and $0.5 \mathrm{mM} \mathrm{CaCl}_{2}, \mathrm{pH} \mathrm{7.35}$. Parasagittal brain slices $(300 \mu \mathrm{m}$ thick) were cut with a microslicer. The slices were kept at $37.0 \pm 0.5^{\circ} \mathrm{C}$ in oxygenated NMDG solution for $10 \mathrm{~min}$, and then transferred to physiological solution (125 mM NaCl, $2.5 \mathrm{~mm} \mathrm{KCl,} 1.25 \mathrm{~mm} \mathrm{NaH}_{2} \mathrm{PO}_{4}, 25 \mathrm{~mm}$ $\mathrm{NaHCO}_{3}, 1 \mathrm{~mm} \mathrm{MgCl}$, $25 \mathrm{~mm}$ glucose, and $2 \mathrm{mM} \mathrm{CaCl}_{2}, \mathrm{pH}$ 7.4, ACSF) for $\sim 0.5-1 \mathrm{~h}$. Finally, slices were equilibrated at room temperature for at least 30-45 min before being transferred to a submerged recording chamber constantly perfused with ACSF bubbled with $95 \% \mathrm{O}_{2} / 5 \% \mathrm{CO}_{2}$ at $33.0 \pm 0.5^{\circ} \mathrm{C}$.
Borosilicate pipettes (5-6 $\mathrm{M} \Omega$ ) filled with intracellular solution were used to record neurons from the dorsal DG visualized under DIC infrared illumination. For mEPSC measurements, the intracellular solution contained $120 \mathrm{~mm}$ potassium gluconate, 10 mм HEPES, 4 mм KCl, 4 mм MgATP, 0.3 mм Na 3 GTP, $10 \mathrm{~mm}$ sodium phosphocreatine, and $0.5 \%$ biocytin, $\mathrm{pH} 7.25 ; 0.5 \mu \mathrm{M}$ TTX and $50 \mu \mathrm{m}$ picrotoxin (Tocris Bioscience) were applied to the bath to block action potential-mediated neurotransmitter release and $\mathrm{GABA}_{\mathrm{A}}$ receptors, respectively.

\section{Morphologic reconstruction}

Neuron morphology was reconstructed and analyzed in a blinded manner after slice recordings as previously described (Jiang et al., 2015; Cadwell et al., 2016). In brief, the slices were fixed in freshly prepared $2.5 \%$ glutaraldehyde $/ 4 \%$ PFA in 0.1 м PBS at $4^{\circ} \mathrm{C}$ for $\sim 7 \mathrm{~d}$. To reveal neuronal morphology, the avidin-biotinperoxidase method was performed. Neurons in the dorsal DG were imaged and reconstructed using a $100 \times$ oil-immersion objective lens and camera lucida system (Neurolucida, MicroBrightField). Dendritic arbor structure and spine density were analyzed using Neurolucida software.

\section{Spine analyses of YFP-expressing neurons}

Brain sections (30 $\mu$ m thick) from 1-month-old male WT;YFP and Tiam1 KO;YFP mice were prepared as described above for immunohistochemistry. DG granule cell dendrites from the dorsal DG were imaged using a Carl Zeiss ApoTome structural illumination epifluorescence microscope with a $63 \times$ oil immersion objective. $Z$ series (35-50 images) were taken at an interval of $0.25 \mu \mathrm{m}$ for each dendrite. Spine morphometric analysis was done in a blinded manner using Imaris software (Bitplane Scientific Software) as previously described (Duman et al., 2013; Um et al., 2014; Tu et al., 2018).

\section{Adult neurogenesis}

WT and Tiam $1 \mathrm{KO}$ mice (2 months old) were intraperitoneally injected with $200 \mathrm{mg} / \mathrm{kg}$ BrdU (Sigma Millipore) once every $24 \mathrm{~h}$ for $4 \mathrm{~d}$. Mice were transcardially perfused with $4 \%$ PFA $14 \mathrm{~d}$ after the first injection to study the production of adult-born granule neurons or $28 \mathrm{~d}$ after first injection to study the survival of the adult-born granule neurons in the DG. Brains were collected, sectioned, and costained with IgG (negative control) or antibodies against BrdU and doublecortin (14 d) or NeuN (28 d). Brain sections (16 per mice, 3 mice per genotype) were imaged using a Carl Zeiss epifluorescence microscope with a $10 \times$ objective. We obtained a $Z$ series of 10 images taken at $1 \mu \mathrm{m}$ intervals, and the maximum intensity projection of the images acquired using the AxioVision microscopy software (Carl Zeiss) was analyzed in a blinded manner.

\section{Mouse behavioral tests}

For behavioral experiments, WT and Tiam 1 KO mice were used at 2-3 months of age. All behavioral tests were performed and analyzed with the experimenter blinded to the genotype.

Open field test. Mice were placed in the center of the open filed $(40 \mathrm{~cm} \times 40 \mathrm{~cm})$ and allowed to explore freely for $30 \mathrm{~min}$. Spontaneous locomotor activity was recorded and analyzed by Versamax system software (Omnitech Electronics). Open Field exploration and total distance traveled were used to assess locomotor activity, while time spent in center area was used to assess anxiety level (Crawley and Paylor, 1997; Bailey and Crawley, 2009). 
Accelerating rotarod test. Mice were placed on top of a horizontally oriented accelerating rotarod, which increased in speed from $4-40 \mathrm{rpm}$ for $5 \mathrm{~min}$ and then maintained $40 \mathrm{rpm}$ for another $5 \mathrm{~min}$. The latency of mice to fall was used to assess their motor learning, coordination, and balance. Animals were tested four trials per day for $2 \mathrm{~d}$, with an interval of $30 \mathrm{~min}$ between each trial (Mulherkar et al., 2017).

Fear conditioning. Mice were placed in a training chamber where they were allowed to explore freely for $2 \mathrm{~min}$. Mice were then subjected to 2 pairings of a $30 \mathrm{~s}$ tone $(85 \mathrm{~dB}$, spaced by $2 \mathrm{~min}$ ) followed immediately by an electrical foot-shock $(0.7 \mathrm{~mA}, 2 \mathrm{~s})$. To test contextual fear memory, 24 h later mice were returned to the training chamber with no shock or tone for $5 \mathrm{~min}$, and their freezing behavior was recorded and analyzed by Freeze Frame software (Coulbourn Instruments). To test for cued fear memory, $2 \mathrm{~h}$ later, mice were placed into a chamber with a novel environment (dim light, vanilla odor, different floor). After a 3 min exploratory period, mice were subjected to the tone for $3 \mathrm{~min}$, and their freezing behavior was recorded and analyzed as done previously (Wehner and Radcliffe, 2004). Naive behavior indicates baseline freezing before training.

Context discrimination. A different cohort of adult mice were subjected to a contextual fear discrimination test, modified from Mulherkar et al. (2017). Mice were placed in the training chamber and allowed to freely explore for $2.5 \mathrm{~min}$, after which they were subjected to a single footshock $(0.7 \mathrm{~mA}, 2 \mathrm{~s})$ with no tone. This process was repeated one time before mice were returned to their home cage. After $24 \mathrm{~h}$, mice were again placed in the training chamber (Context A) for $5 \mathrm{~min}$ with no shock, and their freezing behavior was recorded and analyzed as above. Two hours later, mice were placed in a novel chamber (Context B) for $5 \mathrm{~min}$, and their freezing behavior was again recorded and analyzed. Context discrimination was assessed by determining differences in the percent of time mice spent freezing in Context A versus Context B.

\section{Experimental design and statistical analysis}

All experiments were designed to examine genotype-based effects between Tiam1 KO mice and their WT littermates. To analyze Tiam1 protein level (see Fig. $1 E-G$ ), we used 1-month-old WT and Tiam $1 \mathrm{KO}$ mice of both sexes. For H\&E staining (see Fig. 1H), 2.5-month-old female WT and Tiam1 KO mice were used. For the analysis of dendrite morphology (see Fig. 2), spine density and excitatory synaptic transmission (see Fig. 3C-J), we used 3-week-old (P21) and 6- to 7-week-old (P42-P49) male WT and Tiam1 KO mice. Dendritic spine analysis was also performed on 1-month-old male YFP-expressing WT and Tiam1 KO mice (see Fig. $3 A, B$ ). For the analysis of adult neurogenesis (see Fig. 4), 2-month-old male WT and Tiam1 KO mice were used for BrdU injection. For behavioral experiments (see Fig. 5), 2- to 3-month-old WT and Tiam1 KO mice were tested. Since no behavioral differences were observed between male and female mice of each genotype, data from both sexes were combined. Numbers of mice used in each experiment are specified in the figure legends. Data are mean \pm SEM. Statistical analyses were performed using KaleidaGraph (Synergy Software) or Prism (GraphPad), the details of which are described in the figure legends. Briefly, we used Student's $t$ test when comparing two independent groups and ANOVA with Tukey's post hoc test when comparing multiple groups. $p<0.05$ is considered statistically significant.

\section{Results}

\section{Generation and characterization of mice lacking Tiam 1}

The Rac-GEF Tiam1 is strongly expressed in the developing brain and remains high in adult brain regions undergoing plasticity (Ehler et al., 1997; Tolias et al., 2005). In particular, Tiam1 is enriched in the DG where its expression is highly correlated with DG granule cell maturation (Ehler et al., 1997; Lein et al., 2004; Rao et al., 2019) (Fig. 1A,B). However, the role of Tiam1 in the intact mammalian brain remains unclear. To address this question, we generated a floxed allele of Tiam1 (Tiam $f^{f l f l}$ ) by inserting two loxP sites into a region of the murine Tiam1 gene flanking exon 5 (Fig. 1C,D). Global Tiam1 KO mice were then produced by crossing Tiam $1^{f l / f l}$ mice with Ella-Cre transgenic mice to delete Tiam1 from early embryos (Lakso et al., 1996). To verify Tiam1 loss, we performed Western blot analyses on hippocampal lysates from Tiam1 KO mice and WT littermate controls. While Tiam1 levels were abundant in the hippocampus of 1month-old WT mice, they were undetectable in Tiam1 KO mice, confirming ablation of Tiam1 (Fig. 1E,F). We also performed immunohistochemistry on coronal hippocampal brain sections from 1-month-old WT and Tiam1 KO mice, which showed specific loss of Tiam1 from the DG (Fig. 1G).

Despite the successful ablation of Tiam1, Tiam1 KO mice are viable, fertile, and do not display any gross alterations in brain structure (Fig. 1H). This result is consistent with a previous report demonstrating that global Tiam $1 \mathrm{KO}$ mice are viable and fertile (Malliri et al., 2002), but contradicts a different report showing that Tiam1 KO mice generated using the gene trap method are mostly inviable because of severe defects in brain development (Yoo et al., 2012). Given our results and the results by Malliri et al. (2002), it is likely that other genes in addition to Tiam 1 are affected in the gene trap KO of Tiam1, and that Tiam1 loss alone does not cause lethality or gross abnormalities in brain development.

\section{Tiam 1 promotes the stabilization of DG granule cell dendritic arbors}

The ability of neurons to integrate into a neural circuit and process information appropriately depends on the proper development and stabilization of their dendritic arbors (Branco and Häusser, 2010; Jan and Jan, 2010; Koleske, 2013; Lefebvre et al., 2015). We previously determined that Tiam 1 promotes dendritic arbor growth in dissociated cultures of rat hippocampal neurons (Tolias et al., 2005). Moreover, Tiam1 was recently shown to regulate dendritic patterning of somatosensory PVD neurons in Caenorhabditis elegans (Tang et al., 2019), but its role in the intact mammalian brain has not been established. Since Tiam1 is highly expressed in the DG (Fig. $1 B$ ), we investigated whether it regulates DG granule cell dendritic arbor development. Granule cells in acute hippocampal slices from 6- to 7-week-old (P42P49) WT and Tiam1 KO littermates were filled with biocytin during whole-cell recordings (see below), stained with the avidin-biotin-peroxidase method (Jiang et al., 2015; Cadwell et al., 2016), and their dendritic arbors were reconstructed and analyzed using Sholl analysis (Fig. 2A-C) (Sholl, 1953). We found that DG granule cells from P42-P49 Tiam1 KO mice had markedly simplified dendritic arbors relative to granule cells from WT littermates (Fig. 2A,C). Morphometric analysis (Fig. 2B) also revealed that Tiam1 KO DG granule cells possessed dendrites with decreased total length (WT: $1666.07 \pm 96.07 \mu \mathrm{m}$; KO: $1272.79 \pm 128.90 \mu \mathrm{m})$ (Fig. $2 D$ ), reduced average distance (WT: $158.26 \pm 9.08 \mu \mathrm{m} ; \quad$ KO: $118.27 \pm 11.40 \mu \mathrm{m}$ ) (Fig. $2 E$ ), and 
A

$$
\begin{gathered}
\text { In situ } \\
\text { hybridization }
\end{gathered}
$$

P4

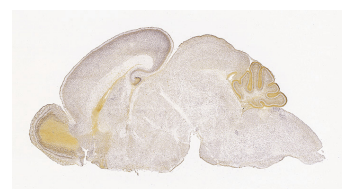

P14
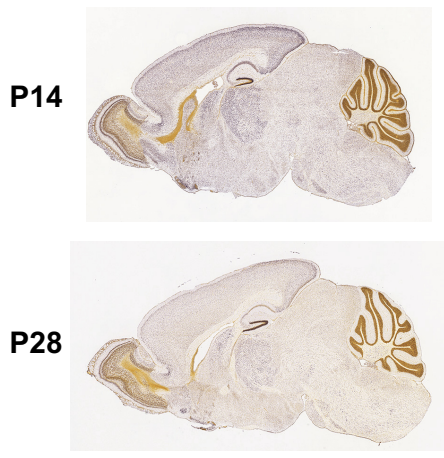

P56
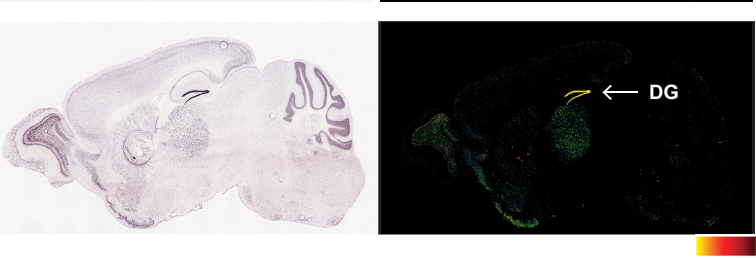

Tiam1 mRNA expression in the developing mouse brain

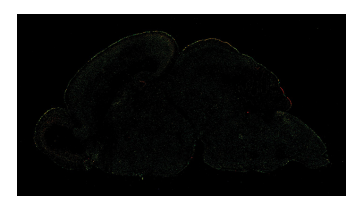

B $\quad \begin{gathered}\text { In situ } \\ \text { hybridization }\end{gathered}$
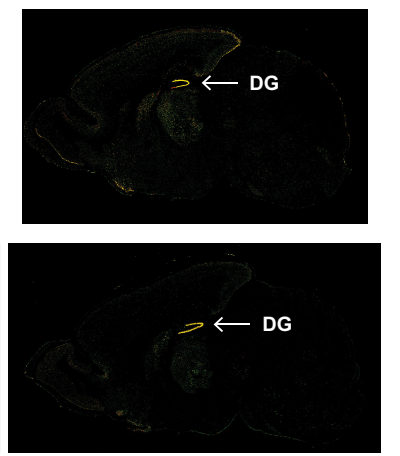

P28
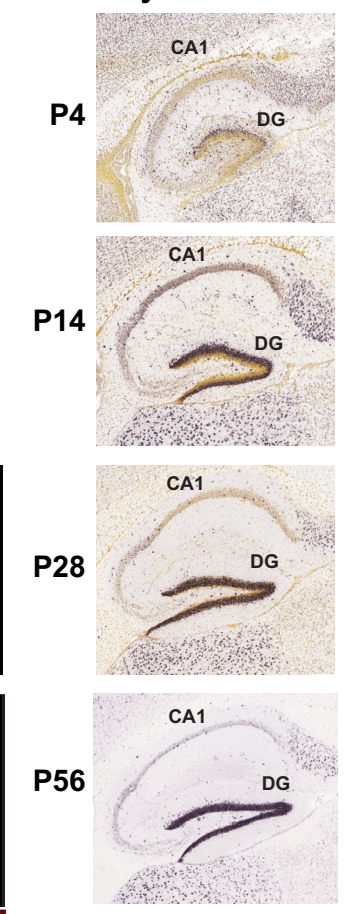
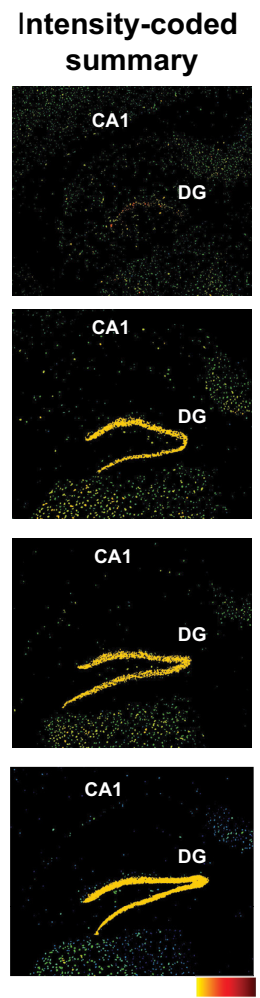

Hippocampal Tiam1 mRNA expression

\section{C}

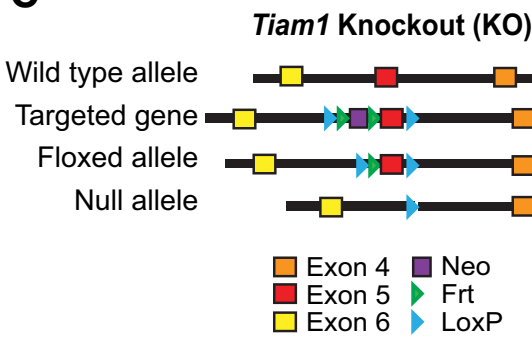

G
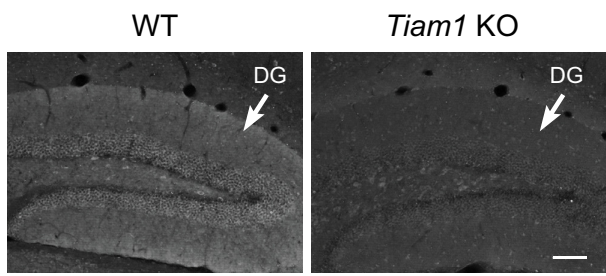

1-month-old mouse hippocampal section Tiam1 Immunohistochemistry
D

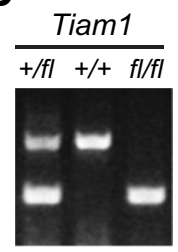

E

$\mathbf{F}$
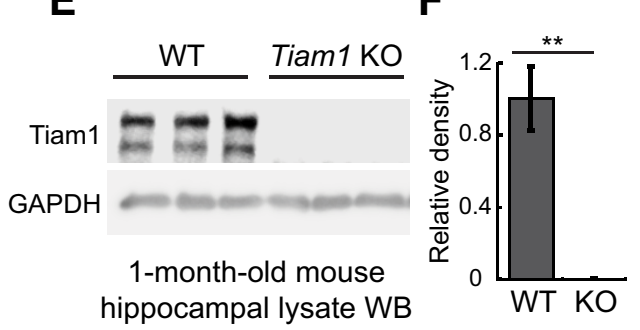

H

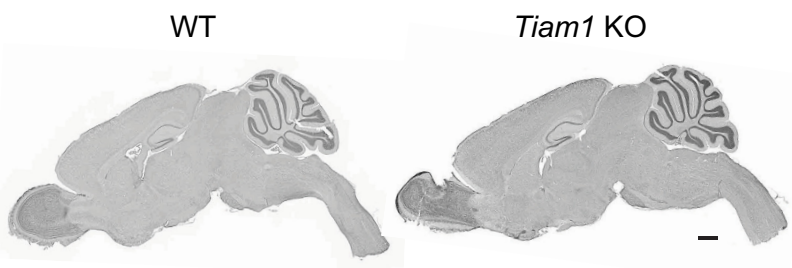

2.5-month-old mouse brain H\&E staining

Figure 1. Generation and characterization of Tiam $1 \mathrm{KO}$ mice. $\boldsymbol{A}$, In situ hybridization (ISH) images (left) of Tiam $1 \mathrm{mRNA}$ in sagittal brain sections from different aged mice demonstrating the developmental expression of Tiam1. Intensity-coded summary images (right) show low (yellow) to high (red) Tiam1 expression. P, Postnatal day. Image credit: Allen Institute. B, Enlarged view of ISH (left) and intensity-coded summary (right) images from $\boldsymbol{A}$ showing Tiam1 expression in the hippocampus, where it is highly enriched in the DG. Image credit: Allen Institute. C, To target the murine Tiam 1 gene, two loxP sites were inserted into a region flanking exon 5 and an internal Frt-flanked neomycin (Neo) cassette was added as a selection marker. The floxed allele

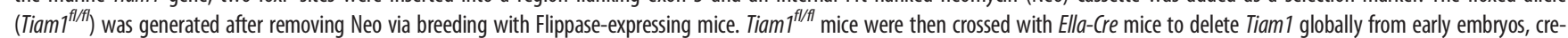
ating Tiam $1^{-1-}$ mice. For all figures, mice are abbreviated as follows: WT, Tiam $1^{-1-}$ (Tiam1 KO or KO). D, PCR analysis of tail DNA prepared from Tiam $1^{+/ t}$, Tiam $1^{+/+}$, and Tiam $1^{f / / 7}$ mice. E, Representative immunoblots of hippocampal lysates from 1-month-old WT and Tiam1 KO mice probed with antibodies against Tiam1 and GAPDH (loading control) demonstrating loss of Tiam1. $\boldsymbol{F}$, Quantification of immunoblots from $\boldsymbol{E}\left(t_{(4)}=5.687, p=0.005\right.$, unpaired $t$ test, $N=3$ mice per genotype). $\boldsymbol{G}$, Representative immunohistochemistry images of coronal hippocampal sections from 1-month-old WT and Tiam1 K0 mice showing loss of Tiam1 staining from the DG of Tiam1 K0 mice. Scale bar, $100 \mu \mathrm{m}$. H, H\&E staining of sagittal brain section from 2.5-monthold WT and Tiam1 KO mice demonstrating no gross changes in brain structure as a result of Tiam1 loss. Scale bar, $1000 \mu \mathrm{m}$. 
A

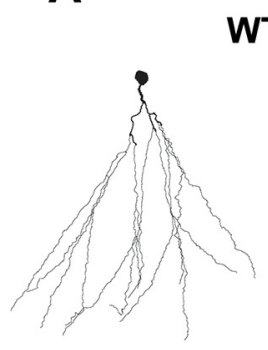

WT

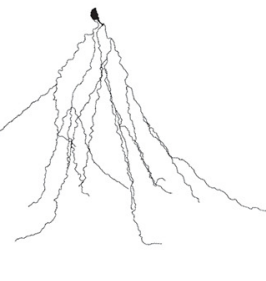

Tiam1 KO

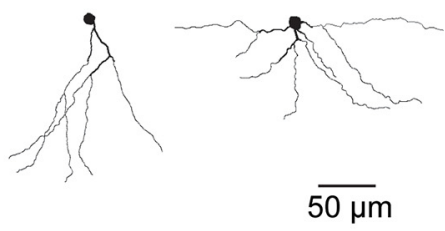

B
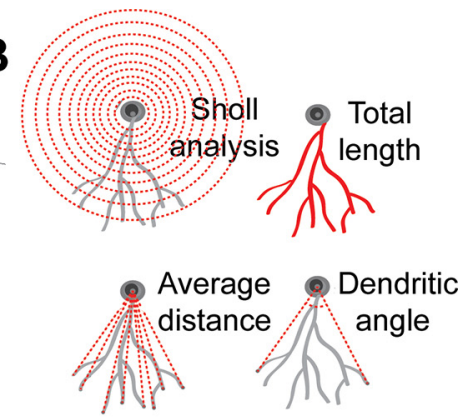

P42 - P49

C

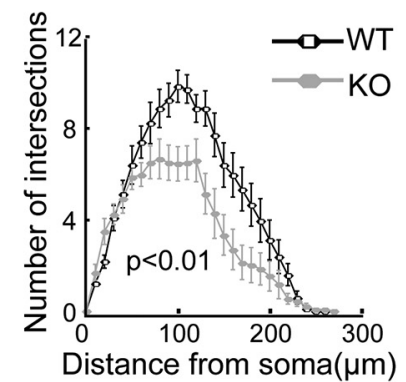

D

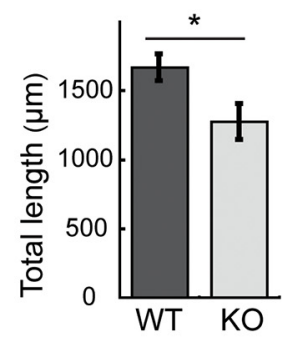

E

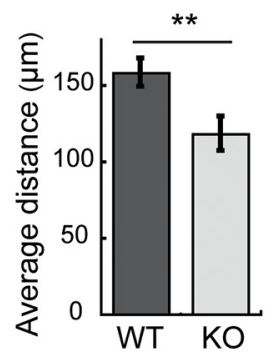

F

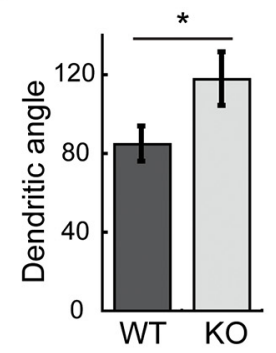

G

WT

Tiam1 KO
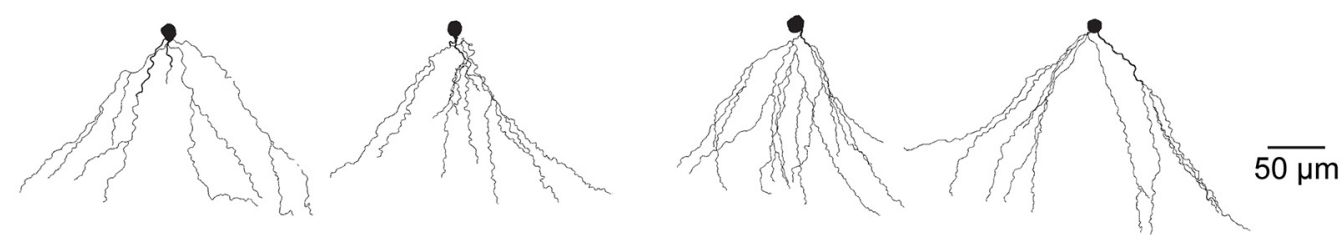

P21

H

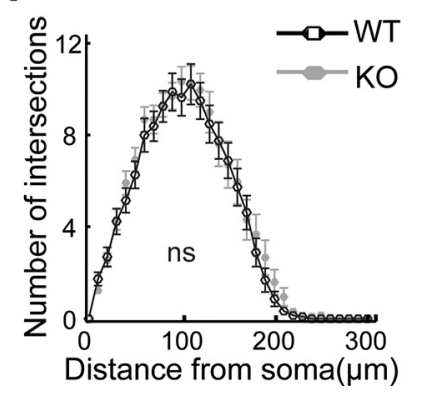

I

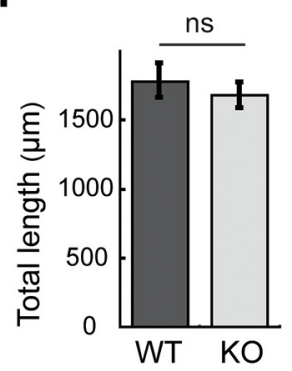

J

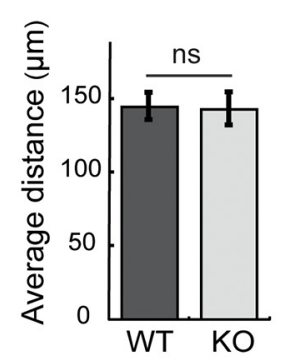

K

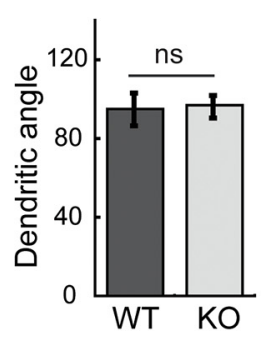

Figure 2. Tiam1 promotes DG granule cell dendritic arbor stabilization. $\boldsymbol{A}$, Representative reconstructed morphologies of biocytin-labeled DG granule cells from 6- to 7-week-old (P42-P49) WT and Tiam $1 \mathrm{KO}$ mice. Scale bar, $50 \mu \mathrm{m}$. B, Schematics illustrating how DG granule cell dendritic arbors (gray) were analyzed via Sholl analysis, total dendritic length, average dendrite distance, and dendritic arbor angle (red). C, Sholl analysis of DG granule cell dendrites from $\boldsymbol{A}$, demonstrating decreased complexity of Tiam1 K0 DG granule cell arbors $\left(F_{(1,74)}=7.914\right.$, $p=0.0061$, two-way ANOVA, $n=19$ neurons per genotype, $N=3$ mice per genotype). $\boldsymbol{D}-\boldsymbol{F}$, Quantification of $(\boldsymbol{D})$ total dendritic length $\left(t_{(40)}=2.494, p=0.0169\right.$, unpaired $t$ test), $(\boldsymbol{E})$ average dendritic distance $\left(t_{(40)}=2.778, p=0.00828\right.$, unpaired $t$ test $)$, and $(\boldsymbol{F})$ average dendritic arbor angle $\left(t_{(40)}=-2.097, p=0.0424\right.$, unpaired $t$ test) of DG granule cells from $\boldsymbol{A}$. WT, $n=23$ neurons, $N=3$ mice; Tiam $1 \mathrm{KO}, n=19$ neurons, $N=3$ mice. $G$, Representative reconstructed morphologies of biocytin-labeled DG granule cells from P21 WT and Tiam $1 \mathrm{KO}$ mice. Scale bar, $50 \mu \mathrm{m}$. $\boldsymbol{H}$, Sholl analysis of DG granule cell dendrites from $\boldsymbol{G}$, demonstrating no difference between P21 WT and Tiam1 KO mice $\left(F_{(1,74)}=7.914, p=0.9442\right.$, two-way ANOVA, WT, $n=21$ neurons, $N=3$ mice; Tiam $1 \mathrm{KO}, n=19$ neurons, $N=3$ mice). $I-K$, Quantification of $(I)$ total dendritic length $\left(t_{(38)}=0.604, p=0.5493\right.$, unpaired $t$ test), $(\boldsymbol{l})$ average dendritic distance $\left(t_{(37)}=0.04374\right.$, $p=0.965$, unpaired $t$ test), and $(K)$ average dendritic arbor angle $\left(t_{(38)}=0.081, p=0.936\right.$, unpaired $t$ test) of DG granule cells from $\mathbf{G}$. WT, $n=21$ neurons, $N=3$ mice; Tiam1 K0, $n=19$ neurons, $N=3$ mice. Data are mean \pm SEM. $* p<0.05$. $* * p<0.01$. Not significant, $p>0.05$. 
A
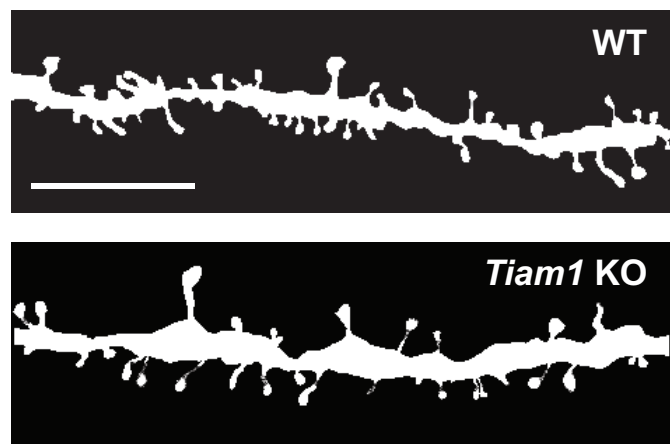

P30 YFP-expressing mice
B

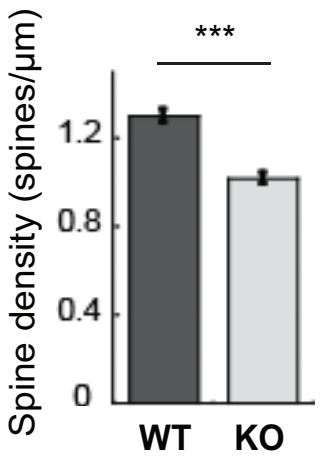

C

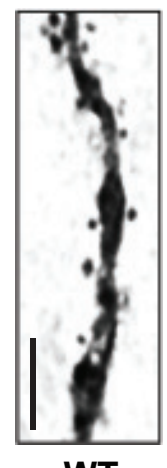

WT

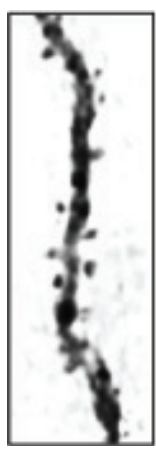

Tiam1

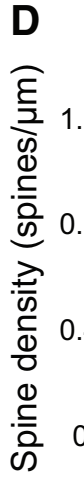

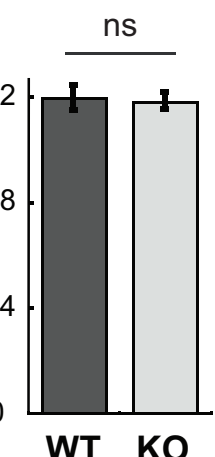

WT KO

KO

P21

\section{G}

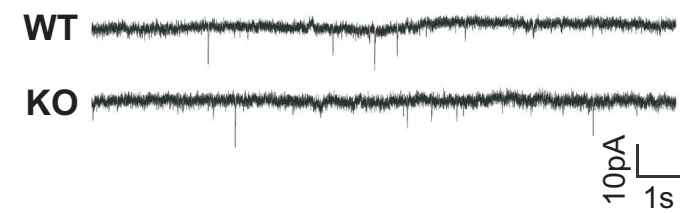

H

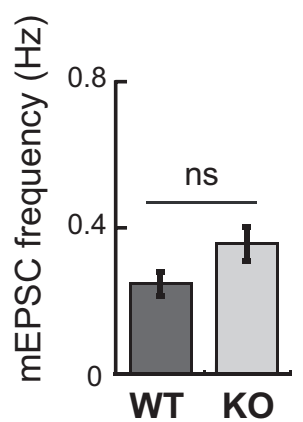

I

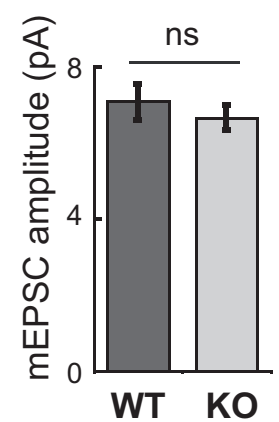

E

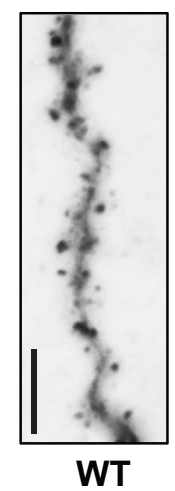

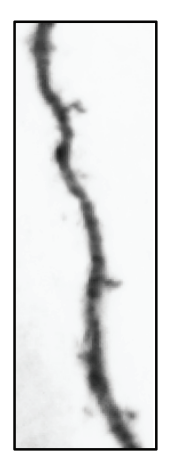

Tiam1

KO

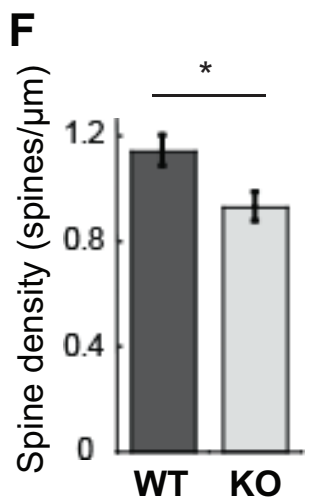

P42 - P49

J

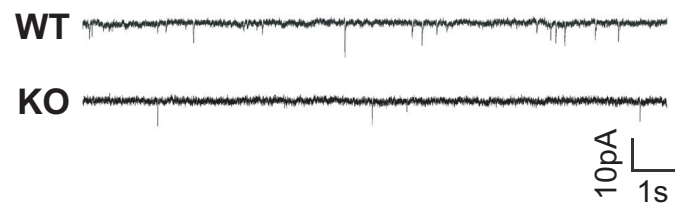

K

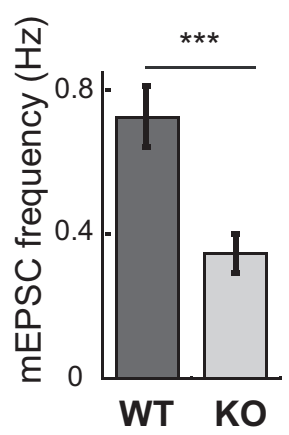

L

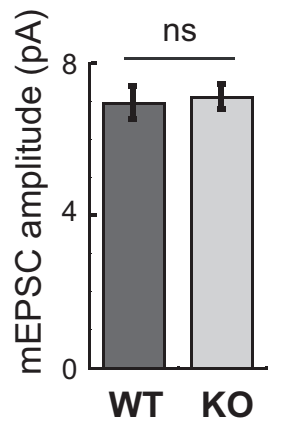

Figure 3. Tiam1 is essential for DG granule cell dendritic spine and excitatory synapse maintenance. $A$, Representative images of spines on DG granule cells from YFP-expressing 1-monthold WT and Tiam $1 \mathrm{KO}$ mice. Scale bar, $5 \mu \mathrm{m}$. B, Quantification of spine density of YFP-expressing DG granule cells from $\boldsymbol{A}$, showing reduced spine density on DG granule cells from Tiam $1 \mathrm{KO}$ mice $\left(t_{(235)}=7.5827, p<0.0001\right.$, unpaired $t$ test, WT, $n=117$ neurons, $N=3$ mice; Tiam1 KO, $n=120$ neurons, $N=3$ mice). C, Representative images of spines from biocytin-filled DG granule cells from P21 WT and Tiam1 K0 mice. Scale bar, $5 \mu \mathrm{m}$. D, Quantification of spine density of biocytin-filled DG granule cells in $\boldsymbol{C}$, showing similar spine densities in WT and Tiam 1 K0 mice at P21 ( $t_{(23)}=0.068, p=0.946$, unpaired $t$ test, WT, $n=13$ neurons, $N=3$ mice; Tiam $1 \mathrm{~K} 0, n=12$ neurons, $N=3$ mice). $\boldsymbol{E}$, Representative images of spines from biocytin-filled DG granule cells from P42-P49 WT and Tiam1 K0 mice. Scale bar, $5 \mu \mathrm{m}$. $\boldsymbol{F}$, Quantification of spine density of biocytin-filled DG granule cells in $\boldsymbol{E}$, confirming reduced spine density on DG granule cells from P42-P49 Tiam1 K0 mice $\left(t_{(39)}=2.627, p=0.0123\right.$, unpaired $t$ test, WT, $n=23$ neurons, $N=3$ mice; Tiam1 K0, $n=17$ neurons, $N=3$ mice). G-I, Representative traces $(\mathbf{G})$ and summary graphs $(H, I)$ of mEPSCs recorded from DG granule cells from P21 WT and Tiam1 K0 mice showing similar excitatory synaptic transmission (frequency: $t_{(41)}=1.841, p=0.073$, unpaired $t$ test; amplitude: $t_{(41)}=0.972, p=0.337$, unpaired $t$ test, WT, $n=21$ neurons, $N=3$ mice; Tiam $1 \mathrm{KO}, n=22$ neurons, $N=3$ mice). $\boldsymbol{J}-\boldsymbol{L}$, Representative traces $(\boldsymbol{J})$ and summary graphs (K,L) of mEPSCs recorded from DG granule cells from P42-P49 WT and Tiam1 K0 mice showing decreased mEPSC frequency for Tiam 1 KO DG granule cells relative to WT DG granule cells at later developmental stages (frequency: $t_{(56)}=3.710, p=0.00048$, unpaired $t$ test; amplitude: $t_{(56)}=0.283, p=0.778$, unpaired $t$ test, WT, $n=31$ neurons, $N=3$ mice; Tiam 1 K0, $n=37$ neuron, $N=3$ mice). Data are mean \pm SEM. $* p<0.05 . * * p<0.01 . * * * p<0.001$. Not significant (ns), $p>0.05$. 

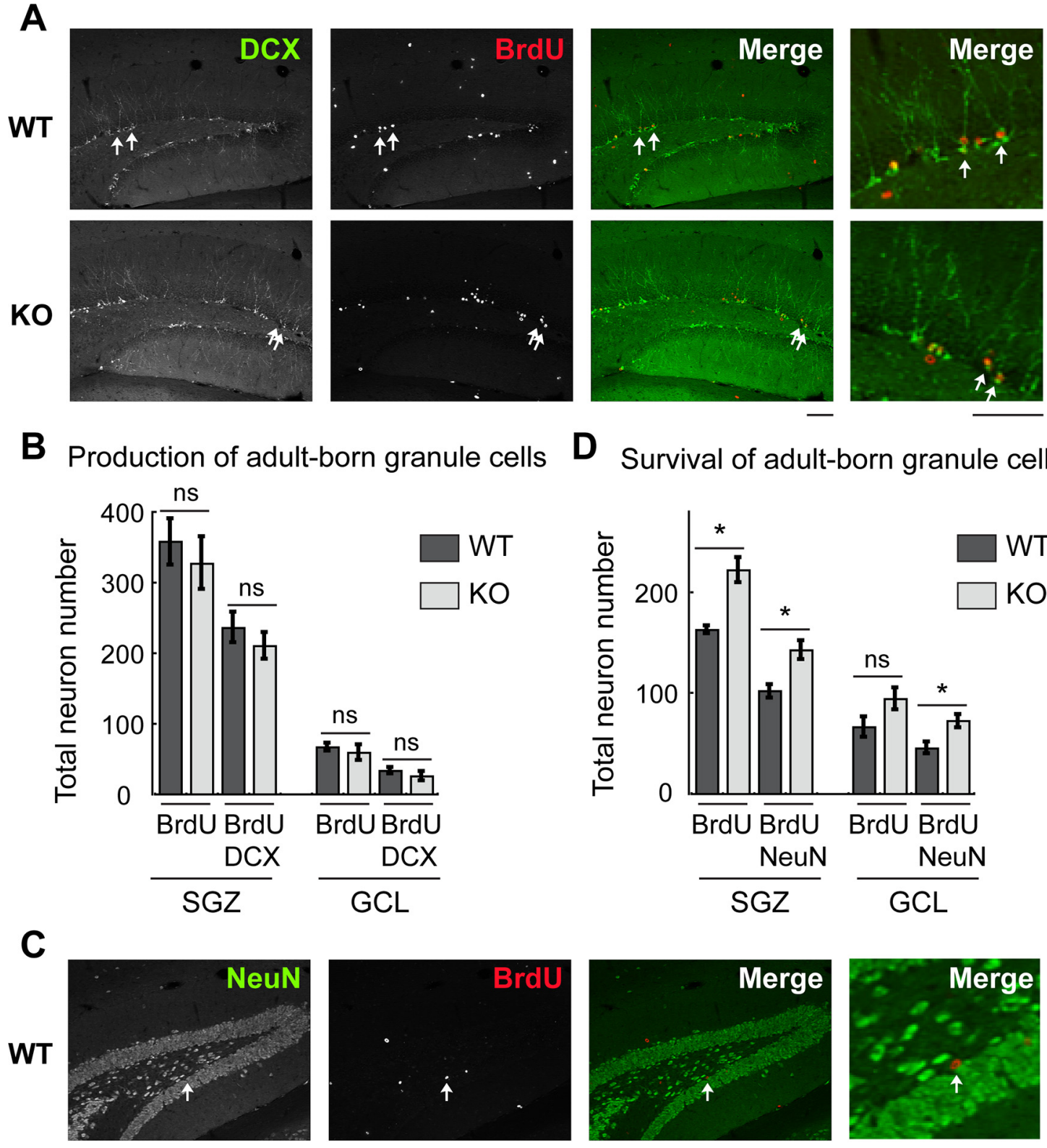

D Survival of adult-born granule cells
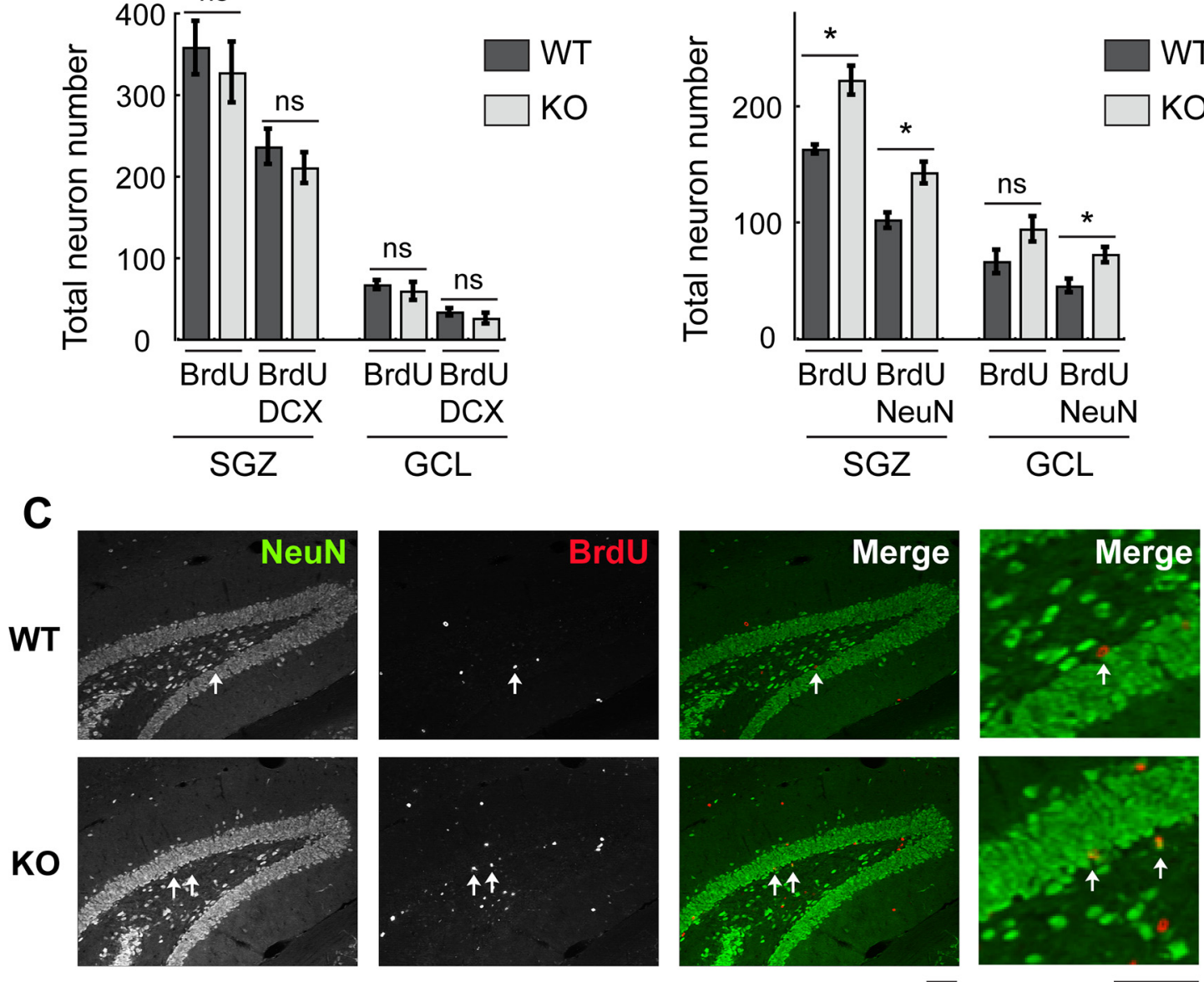

Figure 4. Increased survival of adult-born DG granule cells in Tiam1 KO mice. A, Representative immunohistochemistry images of adult-born granule cells from the DG of 2-month-old WT and Tiam1 KO mice labeled with BrdU and the immature neuronal marker DCX $14 \mathrm{~d}$ after BrdU injection. B, Quantification of neurons labeled with BrdU with or without DCX $14 \mathrm{~d}$ after BrdU injection reflecting newborn neuron production. No difference was detected between WT and Tiam1 K0 mice (BrdU in SGZ: $t_{(4)}=0.609, p=0.576$, BrdU and DCX in SGZ: $t_{(4)}=0.893, p=0.422$; BrdU in GCL: $t_{(4)}=0.617$, $p=0.571$, BrdU and DCX in GCL: $t_{(4)}=0.983, p=0.381$; unpaired $t$ test, 16 hippocampal sections were analyzed per mouse, $N=3$ mice per genotype). $C$, Representative images of adult-born granule cells from the DG of 2-month-old WT and Tiam1 K0 mice labeled with BrdU and the mature neuronal marker NeuN $28 \mathrm{~d}$ after BrdU injection. D, Quantification of neurons labeled with BrdU with or without NeuN $28 \mathrm{~d}$ after BrdU injection reflecting newborn neuron survival. Tiam1 K0 mice possessed significantly more BrdU ${ }^{+}$cells costained with NeuN (BrdU in SGZ: $t_{(4)}=-4.553, p=0.010$, BrdU and NeuN in SGZ: $t_{(4)}=-3.620, p=0.0224$; BrdU in GCL: $t_{(4)}=-1.906, p=0.13$, BrdU and NeuN in GCL: $t_{(4)}=-3.043, p=0.0383$; unpaired $t$ test, 16 hippocampal sections were analyzed per mouse, $N=3$ mice per genotype). Scale bar, $100 \mu \mathrm{m}$. SGZ, Subgranule zone; GCL, granule cell layer. Data are mean \pm SEM. $* p<0.05$. Not significant, $p>0.05$.

increased arbor angle (reflecting altered arbor shape) (WT: $84.52 \pm 8.78$; KO: $117.43 \pm 13.62$ ) (Fig. $2 F$ ). Thus, Tiam1 loss results in wider, shorter, less complex dendritic arbors, suggesting that Tiam1 is required for proper DG granule cell dendrite arborization in vivo.
Dendritic arborization is a dynamic process involving the growth and branching of nascent dendrites, dendrite retraction, and the ultimate stabilization of a subset of branches that form the dendritic tree (Jan and Jan, 2010; Koleske, 2013; Lefebvre et al., 2015). To better understand the specific role Tiam 1 plays in 

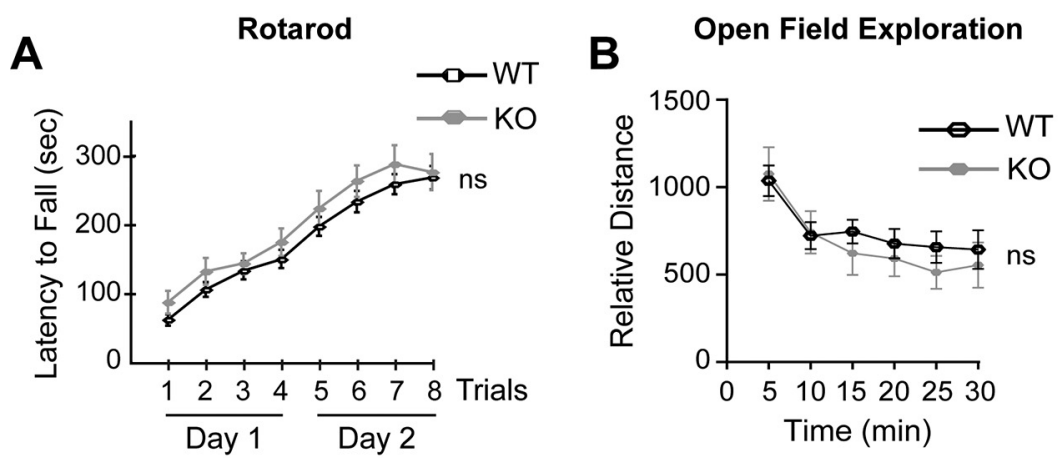

\section{Open Field Distance Traveled \\ C}

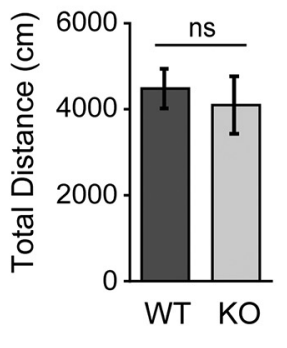

\section{Open Field \\ D Time in Center}

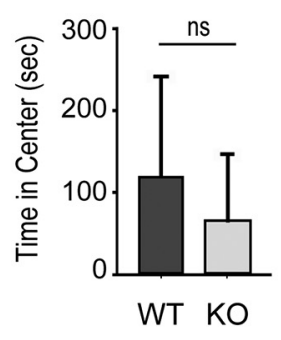

Fear Conditioning Training Stages

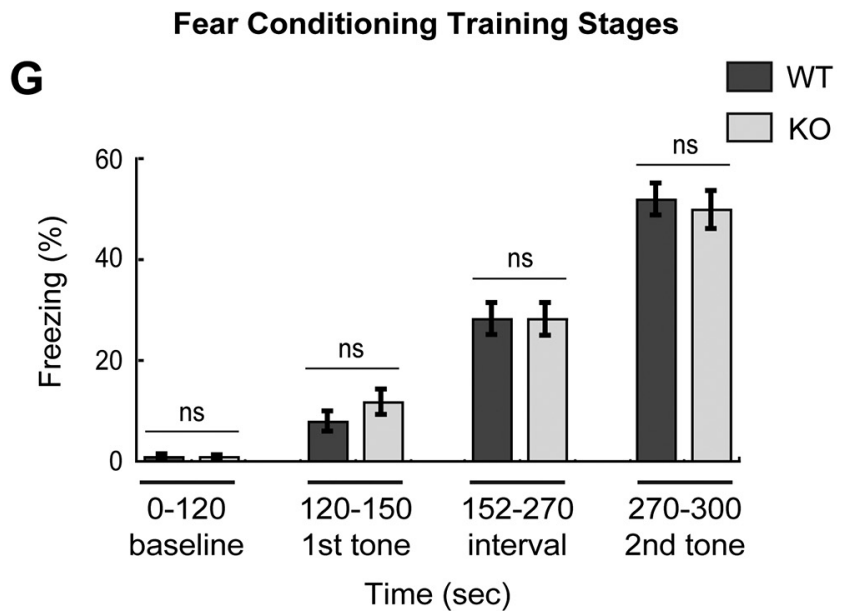

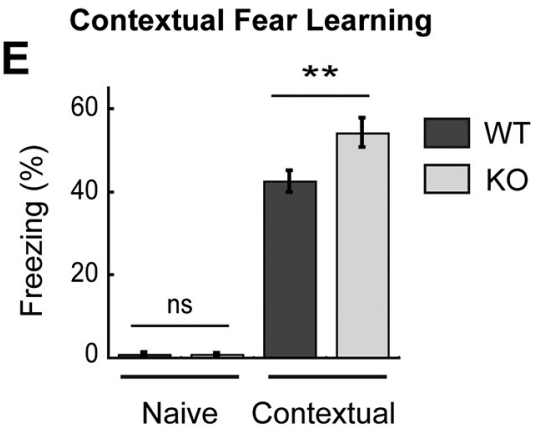

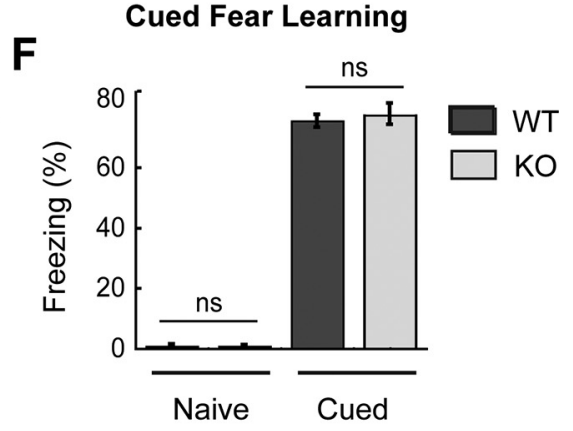

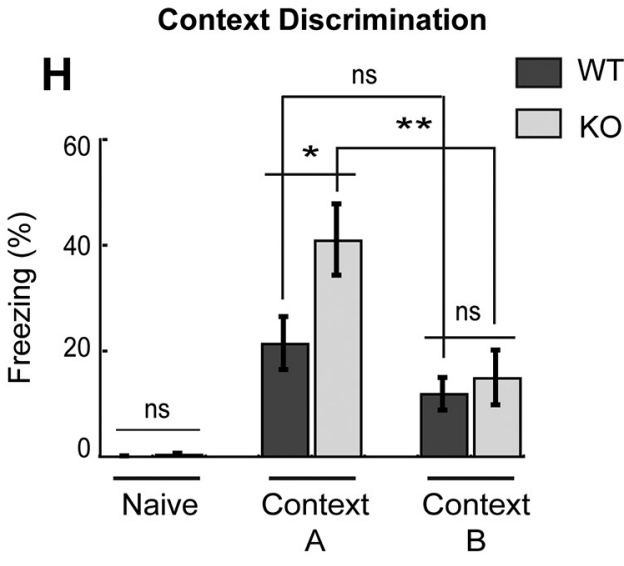

Figure 5. Tiam 1 null mice display enhanced contextual fear memory and context discrimination. $\boldsymbol{A}$, WT and Tiam $1 \mathrm{~K} 0$ mice were tested on an accelerating rotarod for $2 \mathrm{~d}(4$ trials per day), and their motor performance was compared. No significant difference was detected between the two groups of mice $\left(F_{(1,378)}=1.044, p=0.312\right.$, two-way ANOVA, $N=28$ mice per genotype). $\boldsymbol{B}-\boldsymbol{D}$, WT and Tiam $1 \mathrm{KO}$ mice were assessed in an open field test. No statistically significant difference was observed between WT and Tiam $1 \mathrm{~K} 0$ mice for the following measures: (B) open field exploration $\left(F_{(5,70)}=1.186, p=0.325\right.$, two-way ANOVA); $(\boldsymbol{C})$ total distance traveled $\left(t_{(14)}=0.471, p=0.344\right.$, unpaired $t$ test); and $(\boldsymbol{D})$ time spent in the center of the open field (a measure of anxiety) $\left(t_{(14)}=1.025, p=0.299\right.$, unpaired $t$ test). $N=8$ mice per genotype. $\boldsymbol{E}, \boldsymbol{F}$, WT and Tiam $1 \mathrm{~K} 0$ mice were subjected to fear conditioning and then tested for $(\boldsymbol{E})$ contextual fear memory (exposure to the conditioning context $24 \mathrm{~h}$ after training) and $(\boldsymbol{F})$ cued fear memory (exposure to the auditory cue $26 \mathrm{~h}$ after training). Freezing behavior was recorded before training (Naive) and during each test. While both groups of mice exhibited equivalent robust freezing in the cued test, Tiam $1 \mathrm{~K} 0$ mice displayed significantly more freezing in the hippocampal-dependent contextual test (Naive: $t_{(68)}=-0.0134, p=0.989$, unpaired $t$ test; contextual fear memory: $t_{(68)}=-2.730, p=0.00,805$, unpaired $t$ test; cued fear memory: $t_{(68)}=-0.535, p=0.595$, unpaired $t$ test; WT, $N=36$ mice; Tiam $1 \mathrm{KO}, N=34$ mice). $\boldsymbol{G}$, During fear conditioning training for $\boldsymbol{E}$ and $\boldsymbol{F}$, no difference in freezing behavior was detected between WT and Tiam $1 \mathrm{~K} 0$ mice at the different training stages: 0-120 s (before training; baseline); 120-150 s (presentation of tone immediately before first foot-shock; first tone); $152-270 \mathrm{~s}$ (interval between first and second tone-footshock pairing); 270-300 s (presentation of second tone); $\left(F_{(7,272)}=60.720, p<0.0001 ; 0-120 \mathrm{~s}: p=1 ; 120-150 \mathrm{~s}: p=0.969 ; 152-270 \mathrm{~s}: p=1 ; 270-300 \mathrm{~s}: p=0.9993 ;\right.$ WT, N=36 mice; Tiam 1 KO, N=34 mice, one-way ANOVA with Tukey's post hoc test). $\boldsymbol{H}$, WT and Tiam1 KO mice were subjected to a contextual fear discrimination test. Freezing responses of a different cohort of mice were recorded before foot-shock (with no paired tone) (Naive) and $24 \mathrm{~h}$ after foot-shock in the training chamber (Context A) followed by a novel chamber (Context B). Similar to $\boldsymbol{E}$, Tiam 1 $\mathrm{K} 0$ mice spent a greater time freezing in the training chamber (Context A) than WT mice, and Tiam $1 \mathrm{KO}$ mice froze significantly more in Context A than Context $B$, in contrast to WT mice, indicating enhanced context discrimination $\left(F_{(3,42)}=6.203, p=0.0014\right.$; WT in Context A and B: $p=0.434 ; \mathrm{KO}$ in Context A and B: $p=0.009$; WT and K0 in Context A: $p=0.040$; WT and K0 in Context B: $p=0.973$; WT, $N=14$ mice; Tiam1 K0, $N=9$ mice, one-way ANOVA with Tukey's post hoc test). Both male and female mice between 2 and 3 months old were used for the behavioral experiments, since no differences were detected between the two sexes. Data are mean \pm SEM. $* p<0.05$. $* * p<0.01$. $* * * p<0.001$. Not significant, $p>0.05$. 
dendrite development, we also analyzed the dendritic arbors of DG granule cells from younger WT and Tiam1 KO mice at a developmental stage (P21) immediately following a period of extensive dendritic growth (Kerloch et al., 2019). Surprisingly, in contrast to older mice, Sholl analysis revealed that the arbors of DG granule cells from P21 Tiam1 KO mice were similar in complexity to those from P21 WT mice (Fig. 2G,H). Likewise, morphometric analyses indicated that DG granule cell dendritic arbors from P21 WT and Tiam1 KO mice were indistinguishable in terms of total length (WT: $1772.10 \pm 135.71 \mu \mathrm{m}$; KO: $1667.91 \pm$ $101.66 \mu \mathrm{m}$ ) (Fig. $2 I$ ), average distance (WT: $143.37 \pm 4.69 \mu \mathrm{m}$; KO: $143.00 \pm 7.04 \mu \mathrm{m})$ (Fig. 2J), and arbor angle (WT: 93.33.52 \pm 8.64; KO: $94.24 \pm 7.53$ ) (Fig. $2 K$ ). Moreover, by comparing DG granule cell dendrites from younger and older WT and Tiam1 KO mice, we found that only older Tiam1 KO mice displayed altered dendritic complexity relative to the other groups $\left(F_{(1,74)}=7.914, p=0.0063\right)$. Together, these results suggest that DG granule cells in Tiam1 KO mice initially form normal dendritic arbors, but that the dendrites are not properly maintained, resulting in a reduction in dendritic arbor size and complexity by late adolescents. Thus, in vivo, Tiam1 is required for the stabilization rather than the growth of DG granule cell dendritic arbors.

\section{Tiam1 is essential for DG granule cell dendritic spine and excitatory synapse maintenance}

Proper neural circuit assembly and function also depend on the appropriate development of excitatory synapses and the actinrich dendritic spines on which they reside (Lai and Ip, 2013). Previous studies using RNA interference and dominant-negative mutants have established that Tiam1 promotes dendritic spine and excitatory synapse development in cultured hippocampal neurons (Tolias et al., 2005, 2007; Zhang and Macara, 2006; Lai et al., 2012; Duman et al., 2013; Um et al., 2014). Moreover, RNA interference knockdown of Tiam1 from DG granule cells in cultured hippocampal slices was recently shown to reduce synaptic AMPA receptor function and elongate dendritic spines (Rao et al., 2019). However, Tiaml's role in spine and synapse development in the intact brain remains unclear. To determine whether Tiam1 is required for dendritic spine development in vivo, we crossed Tiam 1 KO mice with thy1-YFP (line $\mathrm{H}$ ) transgenic mice that express YFP in sparse neuron populations, enabling visualization of neuron morphology (Fig. 3A) (Feng et al., 2000). High-resolution imaging and three-dimensional spine morphometric analysis were then performed on YFP-expressing DG granule neurons from 1-month-old WT and Tiam1 KO mice. This analysis revealed that in comparison to WT mice, DG granule cells from Tiam1 $\mathrm{KO}$ mice display a marked reduction in spine density (WT: $1.30 \pm 0.03$ spines/ $\mu \mathrm{m}$; KO: $1.02 \pm 0.02$ spines $/ \mu \mathrm{m}$ ) (Fig. $3 B$ ), suggesting that Tiam 1 is required for proper DG granule cell spine development in vivo.

Like dendritic arborization, spine development is a multifaceted process, with the initial formation of long, thin dendritic filopodia followed by shorter, bulbous-headed spines, which continue to appear and disappear throughout postnatal development as they actively participate in synapse formation and elimination (Bhatt et al., 2009; Berry and Nedivi, 2017). As animals mature into adulthood, spine dynamics diminish as spines stabilize while maintaining the ability to undergo remodeling in response to physiological and pathologic conditions (Bhatt et al., 2009; Berry and Nedivi, 2017). To better understand how Tiam1 regulates spine development in vivo, we analyzed the effects of Tiam1 loss on DG granule cell spine density at two different developmental stages: P21 (following extensive spine formation and growth) and P42-P49 (following significant spine stabilization) (Bhatt et al., 2009). Biocytin-filled DG granule cells in acute hippocampal slices from WT and Tiam1 KO mice were reconstructed and analyzed (Jiang et al., 2015; Cadwell et al., 2016). While no difference was detected in the spine density of DG granule neurons from P21 WT and Tiam $1 \mathrm{KO}$ mice (WT: $1.19 \pm 0.06$ spines $/ \mu \mathrm{m}$; KO: $1.18 \pm 0.04$ spines $/ \mu \mathrm{m}$ ), the spine density of DG granule neurons from older, P42-P49 Tiam1 KO mice was significantly lower than that of WT littermates (WT: $1.14 \pm 0.06$ spines $/ \mu \mathrm{m}$; KO: $0.93 \pm 0.06$ spines/ $\mu \mathrm{m}$ ) (Fig. $3 C-F$ ). These results suggest that, like dendritic arbors, Tiam1 promotes the stabilization of DG granule cell dendritic spines in the mouse brain.

Since Tiam1 loss results in a failure to maintain DG granule cell arbors and spines, we next asked whether Tiam 1 ablation also results in fewer DG granule cell glutamatergic synapses and thus reduced excitatory synaptic transmission. To investigate this possibility, we measured AMPA receptor-mediated mEPSCs by performing whole-cell patch-clamp experiments on DG granule cells in acute hippocampal slices from P21 and P42-P49 WT and Tiam $1 \mathrm{KO}$ mice. As with dendritic arbors and spines, we did not detect a statistically significant difference in mEPSC frequency (WT: $0.25 \pm 0.03 \mathrm{~Hz}$; KO: $0.35 \pm 0.05 \mathrm{~Hz}$ ) or amplitude (WT: $5.98 \pm 0.41 \mathrm{pA}$; KO: $5.49 \pm 0.31 \mathrm{pA}$ ) between WT and Tiam1 KO dentate granule cells at P21 (Fig. 3G-I), suggesting that DG granule cell excitatory synapses form normally in Tiam 1 KO mice. However, later in development (P42-P49), we detected a significant decrease in mEPSC frequency (WT: $0.60 \pm 0.07 \mathrm{~Hz}$; KO: $0.26 \pm 0.03 \mathrm{~Hz}$ ) but not amplitude (WT: $5.61 \pm 0.26 \mathrm{pA}$; KO: $5.22 \pm 0.27 \mathrm{pA}$ ) in DG granule cells from Tiam1 KO mice (Fig. 3J-L), suggesting a failure to maintain normal excitatory synaptic transmission. Thus, consistent with our morphologic results, Tiam1 appears to promote the stabilization rather than the formation of DG granule cell excitatory synapses in the developing brain.

\section{Increased survival of adult-born neurons in the DG of Tiam1 KO mice}

The DG is one of the two known brain regions in adult animals where neurogenesis persists (Ming and Song, 2011; Drew et al., 2013). New granule cells are continuously generated throughout life from dividing progenitor cells in the subgranular zone of the DG; and while a large percentage of these adult-born granule cells die, many survive, mature, and integrate into the existing hippocampal circuit (Ming and Song, 2011; Drew et al., 2013). These adult-born DG granule cells are thought to play important roles in learning, memory, and mood regulation (Sahay and Hen, 2007; Deng et al., 2009; Ming and Song, 2011; Frankland and Josselyn, 2016). In order to successfully survive and stably integrate into the existing neural circuit, adult-born granule cells need to compete with mature granule cells for entorhinal cortical inputs (McAvoy et al., 2016). Notably, the downstream target of Tiam1, Rac1, plays important roles in this process. Ablation of Rac1 from adult-born granule cells impairs late dendritic arbor growth and spine maturation (Vadodaria et al., 2013), whereas conditional deletion of Rac1 from mature DG granule cells increases adult-born granule cell survival by decreasing spine density in mature neurons and thus reducing synaptic competition (McAvoy et al., 2016). Since Tiam1 remains highly expressed in the adult DG, we asked whether it also plays a role in the birth and/or development of adult-born DG granule cells. To examine this possibility, we injected 5 '-bromo- 2 ' -deoxyuridine (BrdU, $200 \mathrm{mg} / \mathrm{kg}$ i.p.) into 2-month-old WT and Tiam 1 $\mathrm{KO}$ mice once daily for $4 \mathrm{~d}$. BrdU is a thymidine analog that 
incorporates into dividing cells during DNA synthesis, and thereby acts as a tracer for adult newborn neurons (Wojtowicz and Kee, 2006). At 14 or $28 \mathrm{~d}$ after BrdU labeling, brains were collected, sectioned, and stained for different neuronal markers (Kempermann et al., 2004; von Bohlen Und Halbach, 2007). At $14 \mathrm{~d}$ after injection, we detected a similar number of $\mathrm{BrdU}^{+}$cells that costained with the immature neuronal marker DCX (doublecortin) within the DG of WT and Tiam1 KO mice (Fig. $4 A$, $B)$, suggesting that they produce an equivalent amount of adultborn DG granule cells. However, at $28 \mathrm{~d}$ after injection, Tiam 1 $\mathrm{KO}$ mice possessed significantly more $\mathrm{BrdU}^{+}$cells that costained with the mature neuronal marker NeuN (neuronal nuclear protein) (Fig. $4 C, D$ ), suggesting that the survival rate of adult-born DG granule cells is greater in Tiam 1 KO mice than in WT mice. Thus, Tiam1 loss increases the survival of adult-born DG granule cells without affecting their proliferation. Because Tiam1 expression is more evident in mature DG granule cells than immature ones (Ehler et al., 1997) and mature granule cells in Tiam1 KO mice have simplified dendritic arbors and reduced spine densities as a result of a maintenance failure (Figs. 2 and 3), the increased survival of adult-born DG granule cells in Tiam $1 \mathrm{KO}$ mice is likely due, at least in part, to decreased competition with mature granule cells for synaptic inputs.

\section{Tiam1 null mice display enhanced contextual fear learning and spatial discrimination}

Synapse and dendrite abnormalities and aberrant adult neurogenesis characterize numerous brain disorders and are associated with altered learning and memory in both humans and mice (Deng et al., 2010; Ming and Song, 2011; Penzes et al., 2011; Kulkarni and Firestein, 2012; Lai and Ip, 2013). Since Tiam1 plays a critical role in hippocampal spine and dendrite development and the survival of adult-born DG granule cells, we asked whether mice lacking Tiam1 display any behavioral alterations. To address this question, adult WT and Tiam1 KO mice were subjected to a battery of behavioral tests. As many behavioral tests rely on proper locomotor activity, we first measured motor function in WT and Tiam1 KO mice using the accelerating rotarod (Deacon, 2013). We found that Tiam1 KO mice perform as well as WT littermates on the rotarod (Fig. 5A), suggesting that they do not have deficits in motor coordination, motor learning, or balance. WT and Tiam1 KO mice were also analyzed in an open field test, which assesses exploratory and anxiety-like behavior (Bailey and Crawley, 2009). Like the rotarod results, Tiam1 KO mice performed similar to WT mice in open field exploration, total distance traveled, and time spent in center of the open field (Fig. 5B-D), indicating that Tiam1 KO mice do not possess significant locomotor impairments or altered anxietylike behavior relative to WT animals.

Since the hippocampus, and the DG in particular, plays an important role in learning, memory, and pattern separation, we next subjected WT and Tiam1 KO mice to contextual and auditory (cued) fear conditioning. These tests gauge the ability of mice to learn and remember an association between neutral environmental cues (e.g., chamber, tone) and an aversive experience (e.g., mild foot-shock) by measuring freezing behavior (Wehner and Radcliffe, 2004). Contextual fear conditioning (pairing of context with foot-shock) relies on both the hippocampus and amygdala, while auditory cued fear conditioning (pairing of tone with foot-shock) requires only the amygdala (LeDoux, 2000). Unexpectedly, we found that Tiam1 KO mice froze significantly more than WT littermates when placed in the conditioning chamber $24 \mathrm{~h}$ after fear conditioning training involving 2 foot-shock-tone pairings (WT: $42.4 \pm 2.6 \%$; KO: $54.1 \pm 3.5 \%$ ) (Fig. $5 E$ ). In contrast, no difference in freezing behavior was detected either before training (i.e., naive mice) (Fig. 5E) or during training (Fig. 5G). These results suggest that Tiam1 KO mice possess enhanced hippocampal-dependent contextual fear memory. In contrast to contextual fear memory, WT and Tiam1 KO mice exhibited equivalent freezing behavior in response to the auditory conditioning stimulus (tone) $1 \mathrm{~d}$ after training (WT: $75.3 \pm 2.0 \%$; KO: $77.2 \pm 3.0 \%$ ) (Fig. $5 F$ ), suggesting that Tiam1 KO mice have normal cued fear memory. To assess pattern separation in Tiam $1 \mathrm{KO}$ mice, we also performed a DG-dependent contextual discrimination test, in which a different cohort of mice were subjected to two spaced foot-shocks without a tone in Context A (training chamber), and then tested $24 \mathrm{~h}$ later first in Context A and then $2 \mathrm{~h}$ later in Context B (distinct chamber) (Kheirbek et al., 2012b). Under these conditions, WT mice exhibited only moderate freezing behavior in Context $A$, and were unable to distinguish (i.e., no significant difference in freezing) between Context A and Context B (Fig. 5H). In contrast, Tiam1 KO mice froze significantly more than WT mice in Context A (WT: $21.3 \pm 5.0 \%$; KO $40.9 \pm 6.7 \%$ ) and were able to distinguish (i.e., significant difference in freezing) between Context A and Context B (WT: $9.5 \pm 4.1 \%$ difference; KO: $26.1 \pm 6.0 \%$ difference) (Fig. $5 H$ ). These results suggest that, in addition to enhanced contextual fear memory, Tiam1 KO mice have greater DG-dependent contextual discrimination and thus improved pattern separation. Together, these results suggest that Tiam1 normally restricts contextual fear memory and discrimination.

\section{Discussion}

The DG plays a critical role in fundamental brain processes, such as learning, memory, spatial coding, and pattern separation, while its dysfunction is associated with neuropsychiatric disorders (Hagihara et al., 2013; Lopez-Rojas and Kreutz, 2016). Here, we demonstrate that the DG-enriched Rac-GEF Tiam1 is a key regulator of DG development and function. By generating and characterizing mice lacking Tiam1, we showed that Tiam1 is required for the proper stabilization and maintenance of DG granule cell dendritic arbors, spines, and excitatory synapses late in development. Tiam 1 loss also results in the increased survival, but not generation, of adult-born DG granule cells. Moreover, we found that Tiam1 KO mice display enhanced DG-related behaviors (i.e., contextual fear memory and discrimination). Together, these results suggest that Tiam 1 is essential for regulating DG granule cell maturation, stabilization, and function within hippocampal circuits.

Previously, work from our laboratory and others established Tiam1 as a key regulator of dendrite, spine, and synapse development in hippocampal neurons (Tolias et al., 2005, 2007; Zhang and Macara, 2006; Lai et al., 2012; Duman et al., 2013; Um et al., 2014). Tiam1 promotes the formation and growth of spines and excitatory synapses by coupling synaptic receptors (e.g., NMDAR, EphB, BAI1, TrkB) to Racl signaling pathways that control actin cytoskeletal remodeling (Tolias et al., 2005, 2007; Zhang and Macara, 2006; Lai et al., 2012; Duman et al., 2013). Tiam 1 also interacts with the Rac-GAP Bcr, and together they cooperate to keep synaptic Racl signaling within an optimal range that elicits appropriate spine formation while preventing excessive Rac1-mediated receptor endocytosis and spine loss (Um et al., 2014). Recently, Tiam1 was also shown to regulate synaptic AMPA receptor function and spine length in 


\section{Wild-type}
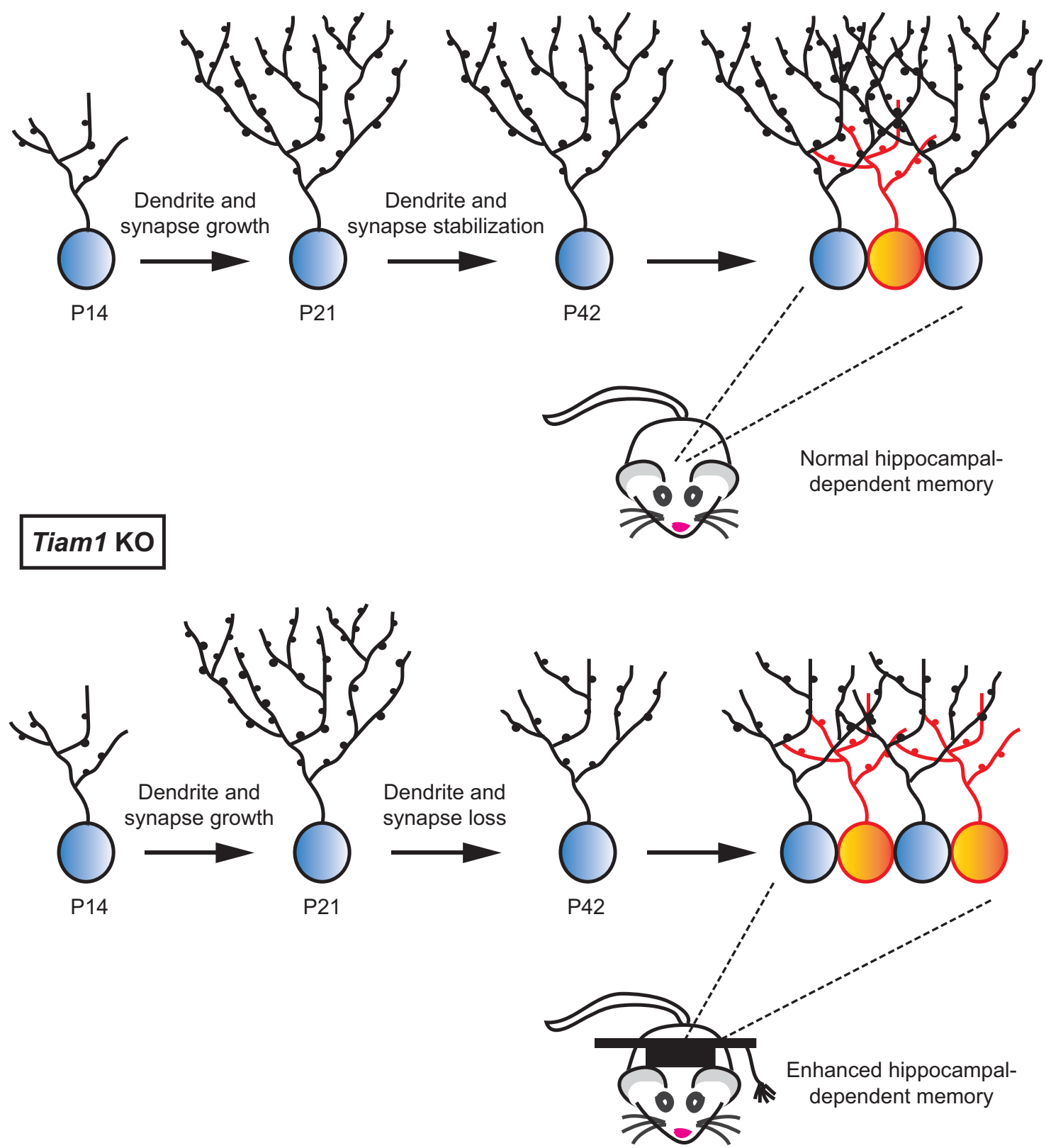

Figure 6. Model of Tiam1's role in regulating DG development and function. During late development, Tiam1 promotes the maturation and stabilization of DG granule cell dendritic arbors and spines, resulting in WT mice with normal excitatory synaptic transmission, adult-born granule cell (orange) survival, and hippocampal-dependent memory. In the absence of Tiam1, the arbors and spines of DG granule cells from Tiam $1 \mathrm{KO}$ mice grow normally but fail to stabilize during a period of activity-dependent refinement, resulting in dendrite and spine loss and reduced excitatory synaptic transmission. Tiam $1 \mathrm{~K} 0$ mice also display increased adult-born granule cell survival, possibly because of decreased competition with mature granule cells (blue) for synaptic input, and enhanced contextual fear memory and context discrimination.

DG granule cells (Rao et al., 2019). However, despite this progress, knowledge about the in vivo roles of Tiam 1 in the intact brain is limited since these studies were primarily conducted in hippocampal dissociated neuron or slice cultures, which do not fully reproduce the complex $3 \mathrm{D}$ architecture and/or maturation of the intact brain. To elucidate Tiam1's function in the brain, we generated Tiam1 KO mice. Morphologic and electrophysiological analyses of these mice revealed that global loss of Tiam1 results in DG granule cells with simplified dendritic arbors, lower spine densities, and reduced excitatory synaptic transmission. Surprisingly, these dendritic and synaptic abnormalities were only detected late in development. Initially, DG granule cells develop normally in Tiam $1 \mathrm{KO}$ mice, resembling WT granule cells at P21. However, the dendrites and spiny synapses of Tiam1 KO DG granule cells fail to stabilize, leading to dendrite and synapse loss by P42. These results indicate that Tiam1 promotes the stabilization and maintenance of DG granule cell dendritic arbors and excitatory synapses late in development during a period of activity-dependent refinement (Fig. 6). Notably, our results are similar to previous reports showing that key molecules involved in integrin signaling, including $\alpha 3, \beta 1$, and ARG, are required in mice for dendritic arbor and spine stabilization 
during this same late developmental period (P21-P42) (Moresco et al., 2005; Sfakianos et al., 2007; Warren et al., 2012; Kerrisk et al., 2013; Koleske, 2013; Lin et al., 2013). While Tiam1 is known to function in integrin signaling to regulate cell-matrix adhesion in non-neuronal cells (Hamelers et al., 2005; O’Toole et al., 2011; Wang et al., 2012), whether it regulates dendrite and/or synapse stability in neurons in response to integrin signaling or in a parallel pathway remains to be determined. It is also not clear why dendritic and synaptic defects are detected at an earlier developmental stage in cultured hippocampal neurons lacking Tiam1 than in Tiam1 KO mice (Tolias et al., 2005, 2007; Zhang and Macara, 2006; Lai et al., 2012; Duman et al., 2013; Um et al., 2014). It is possible that within the more complex $3 \mathrm{D}$ environment of the brain, which is enriched in extracellular matrix and glia, neurons are able to compensate for Tiam1 loss during the earlier growth phase of development. Alternatively, the sparse loss of Tiam1 that occurs in transfected neuron cultures may place neurons lacking Tiam1 at a larger competitive disadvantage than global Tiam1 loss. Additional research is needed to investigate these and other possibilities.

Our results also implicate Tiam 1 in the regulation of adult neurogenesis. Neural stem cells in the DG continue to generate new neurons throughout life, which is thought to be important for learning, memory, pattern separation, and mood regulation (Sahay and Hen, 2007; Deng et al., 2010; Ming and Song, 2011). During maturation, adult-born GC granule cells exhibit enhanced excitability and plasticity, which may facilitate their functional integration, enabling long-term changes in the network (Ramirez-Amaya et al., 2006; Wiskott et al., 2006). The production and survival of adult-born granule cells are influenced by a variety of factors, including age, exercise, environmental enrichment, antidepressants, stress, and disease (Deng et al., 2010; Ming and Song, 2011). To successfully survive and integrate into existing neural circuits, adult-born DG granule cells must compete with mature granule cells for synaptic inputs, and recently it was shown that reducing this competition by inducing spine elimination in mature granule cells enhances the survival of adult-born granule cells (McAvoy et al., 2016). As Tiam1 is highly expressed throughout life in DG granule cells (Fig. 1A) (Ehler et al., 1997), we examined whether adult neurogenesis was affected in Tiam1 KO mice. Interestingly, we found that loss of Tiam1 increases the survival of adult-born neurons, but not their production. Since mature, but not developing, granule cells in Tiam1 KO mice possess significantly simplified dendritic arbors and reduced spine densities, it is likely that the increased survival of adultborn granule cells in Tiam $1 \mathrm{KO}$ mice is due, at least in part, to decreased synaptic competition with mature granule cells.

Tiam1, Rac1, and the Tiam1-associated Rac-GAP Bcr have all been implicated in neuropsychiatric disorders, and mice lacking Racl or Bcr exhibit learning and memory deficits (Voncken et al., 1998; Aston et al., 2005; Hashimoto et al., 2005; Mikhail et al., 2007; Chahrour et al., 2008; Masui et al., 2008; Haditsch et al., 2009; Chen et al., 2010; Oh et al., 2010; Bongmba et al., 2011; Martinez and Tejada-Simon, 2011; Ahmed et al., 2013; Chandra et al., 2013; De Rubeis et al., 2013; Golden et al., 2013; Liu et al., 2016; Vacca et al., 2016). We therefore asked whether loss of Tiam1 alters mouse behavior. Since DG granule cells in older adolescent Tiam1 KO mice possess dendrite and synapse abnormalities that frequently accompany learning and memory impairments (Penzes et al., 2011; Kulkarni and Firestein, 2012), we initially expected adult Tiam $1 \mathrm{KO}$ mice to perform poorly on DG-dependent behavioral tests. Surprisingly, however, Tiam1
KO mice display greater contextual fear memory and context discrimination compared with WT mice. This enhanced performance could potentially be explained by the increased survival of adult-born DG granule cells in the Tiam1 KO mice, since elevated adult hippocampal neurogenesis is associated with improved learning, memory, and/or pattern separation (Deng et al., 2009, 2010; Aimone et al., 2011; Sahay et al., 2011a,b). However, further investigation is needed to determine how Tiam1 loss increases adult-born DG granule cell survival, whether mature DG granule cells maintain their dendrite and synapse abnormalities throughout adulthood, and whether these or other alterations in Tiam1 KO mice underlie their enhanced contextual memory and discrimination abilities.

Tiam1 shares a number of similarities with Kalirin-7, another neuronal Rac-GEF. Both GEFs localize to dendritic spines, interact with common synaptic receptors (e.g., NMDARs, EphB), and mediate Rac1-dependent spine and synapse development (Penzes et al., 2001, 2003; Tolias et al., 2005, 2007; Xie et al., 2007; Kiraly et al., 2011; Lemtiri-Chlieh et al., 2011; Um et al., 2014). Surprisingly, however, the phenotypes displayed by Tiam $1 \mathrm{KO}$ mice differ markedly from those reported for Kalirin$7 \mathrm{KO}$ mice or mice lacking all KALRN splice variants, including Kalirin-7 (KALRN KO mice). While global loss of Tiam1 and Kalirin-7 both results in neurons with reduced spine density, the effect was observed in distinct brain regions and neuronal subtypes (DG granule cells in Tiam1 KO mice, CA1 pyramidal neurons in Kalirin-7 $\mathrm{KO}$ mice, and cortical pyramidal neurons in KALRN KO mice) (Ma et al., 2008; Xie et al., 2010, 2011). The behavioral phenotypes of these mice are also drastically different. Whereas Tiam1 KO mice display enhanced contextual fear memory and context discrimination, the Kalirin-7 and KALRN KO mice both exhibit impaired contextual fear learning (Ma et al., 2008; Xie et al., 2011). Likewise, mice lacking the Rac1/ Cdc42-GEF $\alpha$ PIX/Arhgef6 possess CA1 pyramidal neurons with elongated dendrites, increased spine density, and decreased excitatory synapse number, and they display impaired learning on complex spatial tasks (Ramakers et al., 2012). These phenotypic differences highlight the distinct roles Rac-GEFs play in the brain, likely because of their differential expression profiles, subcellular locations, and association with discrete signaling complexes (Tolias et al., 2011; Duman et al., 2015). Interestingly, the phenotypes exhibited by Tiam1 KO mice also largely oppose those seen in mice lacking Bcr, the Rac-GAP that interacts with Tiam1. Specifically, Bcr KO mice display increased spine and synapse densities and deficits in spatial and object recognition memory (Oh et al., 2010; Um et al., 2014). Moreover, the dendrites of cultured hippocampal neurons from $\mathrm{Bcr}$ KO mice show increased arborization (Park et al., 2012; Duman et al., 2019). These observations are consistent with our previous finding that Bcr restricts Tiam1-induced Rac1 signaling (Narayanan et al., 2013; Um et al., 2014) and lend support to the idea that Tiam1 and $\mathrm{Bcr}$ cooperate to regulate Racl-dependent processes in the brain.

The finding that Tiam1 loss enhances contextual learning and memory and context discrimination is particularly intriguing given that Tiam1 is a well-established target for protein degradation (Boissier and Huynh-Do, 2014). For example, Tiam1 interacts with several E3 ubiquitin ligase complexes, including $\mathrm{SCF}^{\beta \mathrm{TrCP}}$ and $\mathrm{CUL} 3^{\mathrm{KBTBD6} / 7}$, resulting in its ubiquitylation and proteasomal degradation (Magliozzi et al., 2014; Zhu et al., 2014; Genau et al., 2015; Diamantopoulou et al., 2017). Tiam1 abundance is also negatively regulated by calpain- and caspase-mediated cleavage (Qi et al., 2001; Woodcock et al., 2009). Thus, in 
the brain, Tiam1 may be targeted for degradation in response to stimuli that enhance cognitive function. Indeed, cocaine exposure that induces behavioral plasticity also reduces Tiam1 levels in the nucleus accumbens, a brain region critical for rewardrelated behavior (Dietz et al., 2012; Chandra et al., 2013). On the other hand, Tiam1 is overexpressed in individuals with Down syndrome and in Down syndrome mouse models (Ives et al., 1998; Lockstone et al., 2007; Siddiqui et al., 2008; Ahmed et al., 2013, 2015). It is possible that elevated levels of Tiam1 contribute to the learning and memory deficits associated with Down syndrome. In the future, it will be interesting to determine whether Tiam1 could serve as a therapeutic target for the treatment of brain disorders involving memory impairments.

\section{References}

Ahmed MM, Dhanasekaran AR, Tong S, Wiseman FK, Fisher EM, Tybulewicz VL, Gardiner KJ (2013) Protein profiles in Tc1 mice implicate novel pathway perturbations in the Down syndrome brain. Hum Mol Genet 22:1709-1724.

Ahmed MM, Dhanasekaran AR, Block A, Tong S, Costa AC, Stasko M, Gardiner KJ (2015) Protein dynamics associated with failed and rescued learning in the Ts65Dn mouse model of Down syndrome. PLoS One 10: e0119491.

Aimone JB, Deng W, Gage FH (2011) Resolving new memories: a critical look at the dentate gyrus, adult neurogenesis, and pattern separation. Neuron 70:589-596.

Amaral DG, Scharfman HE, Lavenex P (2007) The dentate gyrus: fundamental neuroanatomical organization (dentate gyrus for dummies). Prog Brain Res 163:3-22.

Aston C, Jiang L, Sokolov BP (2005) Transcriptional profiling reveals evidence for signaling and oligodendroglial abnormalities in the temporal cortex from patients with major depressive disorder. Mol Psychiatry 10:309-322.

Bailey KR, Crawley JN (2009) Anxiety-related behaviors in mice. In: Methods of behavior analysis in neuroscience: frontiers in neuroscience, Ed 2 (Buccafusco JJ, ed). Boca Raton, FL: CRC/Taylor and Francis.

Berger T, Lee H, Young AH, Aarsland D, Thuret S (2020) Adult hippocampal neurogenesis in major depressive disorder and Alzheimer's disease. Trends Mol Med 26:803-818.

Berry KP, Nedivi E (2017) Spine dynamics: are they all the same? Neuron 96:43-55.

Bhatt DH, Zhang S, Gan WB (2009) Dendritic spine dynamics. Annu Rev Physiol 71:261-282.

Bishop AL, Hall A (2000) Rho GTPases and their effector proteins. Biochem J 348:241-255.

Boissier P, Huynh-Do U (2014) The guanine nucleotide exchange factor Tiam1: a Janus-faced molecule in cellular signaling. Cell Signal 26:483491.

Bongmba OY, Martinez LA, Elhardt ME, Butler K, Tejada-Simon MV (2011) Modulation of dendritic spines and synaptic function by Rac1: a possible link to Fragile X syndrome pathology. Brain Res 1399:79-95.

Branco T, Häusser M (2010) The single dendritic branch as a fundamental functional unit in the nervous system. Curr Opin Neurobiol 20:494-502.

Cadwell CR, Palasantza A, Jiang X, Berens P, Deng Q, Yilmaz M, Reimer J, Shen S, Bethge M, Tolias KF, Sandberg R, Tolias AS (2016) Electrophysiological, transcriptomic and morphologic profiling of single neurons using Patch-seq. Nat Biotechnol 34:199-203.

Cahill ME, Xie Z, Day M, Photowala H, Barbolina MV, Miller CA, Weiss C, Radulovic J, Sweatt JD, Disterhoft JF, Surmeier DJ, Penzes P (2009) Kalirin regulates cortical spine morphogenesis and disease-related behavioral phenotypes. Proc Natl Acad Sci USA 106:13058-13063.

Chahrour M, Jung SY, Shaw C, Zhou X, Wong ST, Qin J, Zoghbi HY (2008) $\mathrm{MeCP} 2$, a key contributor to neurological disease, activates and represses transcription. Science 320:1224-1229.

Chandra R, Lenz JD, Gancarz AM, Chaudhury D, Schroeder GL, Han MH, Cheer JF, Dietz DM, Lobo MK (2013) Optogenetic inhibition of D1R containing nucleus accumbens neurons alters cocaine-mediated regulation of Tiam1. Front Mol Neurosci 6:13.

Chen LY, Rex CS, Babayan AH, Kramár EA, Lynch G, Gall CM, Lauterborn JC (2010) Physiological activation of synaptic Rac $>$ PAK (p-21 activated kinase) signaling is defective in a mouse model of fragile $\mathrm{X}$ syndrome. J Neurosci 30:10977-10984.

Crawley JN, Paylor R (1997) A proposed test battery and constellations of specific behavioral paradigms to investigate the behavioral phenotypes of transgenic and knockout mice. Horm Behav 31:197-211.

De Rubeis S, Pasciuto E, Li KW, Fernández E, Di Marino D, Buzzi A, Ostroff LE, Klann E, Zwartkruis FJ, Komiyama NH, Grant SG, Poujol C, Choquet D, Achsel T, Posthuma D, Smit AB, Bagni C (2013) CYFIP1 coordinates mRNA translation and cytoskeleton remodeling to ensure proper dendritic spine formation. Neuron 79:1169-1182.

Deacon RM (2013) Measuring motor coordination in mice. J Vis Exp 75: e2609.

Deng W, Saxe MD, Gallina IS, Gage FH (2009) Adult-born hippocampal dentate granule cells undergoing maturation modulate learning and memory in the brain. J Neurosci 29:13532-13542.

Deng W, Aimone JB, Gage FH (2010) New neurons and new memories: how does adult hippocampal neurogenesis affect learning and memory? Nat Rev Neurosci 11:339-350.

Diamantopoulou Z, White G, Fadlullah MZ, Dreger M, Pickering K, Maltas J, Ashton G, MacLeod R, Baillie GS, Kouskoff V, Lacaud G, Murray GI, Sansom OJ, Hurlstone AF, Malliri A (2017) TIAM1 antagonizes TAZ/ YAP both in the destruction complex in the cytoplasm and in the nucleus to inhibit invasion of intestinal epithelial cells. Cancer Cell 31:621-634. e6.

Dietz DM, Sun H, Lobo MK, Cahill ME, Chadwick B, Gao V, Koo JW, Mazei-Robison MS, Dias C, Maze I, Damez-Werno D, Dietz KC, Scobie KN, Ferguson D, Christoffel D, Ohnishi Y, Hodes GE, Zheng Y, Neve RL, Hahn KM, et al. (2012) Rac1 is essential in cocaine-induced structural plasticity of nucleus accumbens neurons. Nat Neurosci 15:891-896.

Drew LJ, Fusi S, Hen R (2013) Adult neurogenesis in the mammalian hippocampus: why the dentate gyrus? Learn Mem 20:710-729.

Duman JG, Tzeng CP, Tu YK, Munjal T, Schwechter B, Ho TS, Tolias KF (2013) The adhesion-GPCR BAI1 regulates synaptogenesis by controlling the recruitment of the Par3/Tiam1 polarity complex to synaptic sites. J Neurosci 33:6964-6978.

Duman JG, Mulherkar S, Tu YK, X Cheng J, Tolias KF (2015) Mechanisms for spatiotemporal regulation of Rho-GTPase signaling at synapses. Neurosci Lett 601:4-10.

Duman JG, Mulherkar S, Tu YK, Erikson KC, Tzeng CP, Mavratsas VC, Ho TS, Tolias KF (2019) The adhesion-GPCR BAI1 shapes dendritic arbors via Bcr-mediated RhoA activation causing late growth arrest. Elife 8: e47566.

Ehler E, van Leeuwen F, Collard JG, Salinas PC (1997) Expression of Tiam-1 in the developing brain suggests a role for the Tiam-1-Rac signaling pathway in cell migration and neurite outgrowth. Mol Cell Neurosci 9:1-12.

Feng G, Mellor RH, Bernstein M, Keller-Peck C, Nguyen QT, Wallace M, Nerbonne JM, Lichtman JW, Sanes JR (2000) Imaging neuronal subsets in transgenic mice expressing multiple spectral variants of GFP. Neuron 28:41-51.

Frankland PW, Josselyn SA (2016) Hippocampal neurogenesis and memory clearance. Neuropsychopharmacology 41:382-383.

Genau HM, Huber J, Baschieri F, Akutsu M, Dötsch V, Farhan H, Rogov V, Behrends C (2015) CUL3-KBTBD6/KBTBD7 ubiquitin ligase cooperates with GABARAP proteins to spatially restrict TIAM1-RAC1 signaling. Mol Cell 57:995-1010.

Golden SA, Christoffel DJ, Heshmati M, Hodes GE, Magida J, Davis K, Cahill ME, Dias C, Ribeiro E, Ables JL, Kennedy PJ, Robison AJ, Gonzalez-Maeso J, Neve RL, Turecki G, Ghose S, Tamminga CA, Russo SJ (2013) Epigenetic regulation of RAC1 induces synaptic remodeling in stress disorders and depression. Nat Med 19:337-344.

Gonçalves JT, Schafer ST, Gage FH (2016) Adult neurogenesis in the hippocampus: from stem cells to behavior. Cell 167:897-914.

Haditsch U, Leone DP, Farinelli M, Chrostek-Grashoff A, Brakebusch C, Mansuy IM, McConnell SK, Palmer TD (2009) A central role for the small GTPase Racl in hippocampal plasticity and spatial learning and memory. Mol Cell Neurosci 41:409-419.

Hagihara H, Takao K, Walton NM, Matsumoto M, Miyakawa T (2013) Immature dentate gyrus: an endophenotype of neuropsychiatric disorders. Neural Plast 2013:318596.

Hamelers IH, Olivo C, Mertens AE, Pegtel DM, van der Kammen RA, Sonnenberg A, Collard JG (2005) The Rac activator Tiam1 is required for 
(alpha)3(beta)1-mediated laminin-5 deposition, cell spreading, and cell migration. J Cell Biol 171:871-881.

Hashimoto R, Okada T, Kato T, Kosuga A, Tatsumi M, Kamijima K, Kunugi $\mathrm{H}$ (2005) The breakpoint cluster region gene on chromosome 22q11 is associated with bipolar disorder. Biol Psychiatry 57:1097-1102.

Hollands C, Bartolotti N, Lazarov O (2016) Alzheimer's disease and hippocampal adult neurogenesis: exploring shared mechanisms. Front Neurosci 10:178.

Ives JH, Dagna-Bricarelli F, Basso G, Antonarakis SE, Jee R, Cotter F, Nizõetić D (1998) Increased levels of a chromosome 21-encoded tumour invasion and metastasis factor (TIAM1) mRNA in bone marrow of Down syndrome children during the acute phase of AML(M7). Genes Chromosomes Cancer 23:61-66.

Jan YN, Jan LY (2010) Branching out: mechanisms of dendritic arborization. Nat Rev Neurosci 11:316-328.

Jiang X, Shen S, Cadwell CR, Berens P, Sinz F, Ecker AS, Patel S, Tolias AS (2015) Principles of connectivity among morphologically defined cell types in adult neocortex. Science 350:aac9462.

Jonas P, Lisman J (2014) Structure, function, and plasticity of hippocampal dentate gyrus microcircuits. Front Neural Circuits 8:107.

Kempermann G, Jessberger S, Steiner B, Kronenberg G (2004) Milestones of neuronal development in the adult hippocampus. Trends Neurosci 27:447-452.

Kerloch T, Clavreul S, Goron A, Abrous DN, Pacary E (2019) Dentate granule neurons generated during perinatal life display distinct morphological features compared with later-born neurons in the mouse hippocampus. Cereb Cortex 29:3527-3539.

Kerrisk ME, Greer CA, Koleske AJ (2013) Integrin $\alpha 3$ is required for late postnatal stability of dendrite arbors, dendritic spines and synapses, and mouse behavior. J Neurosci 33:6742-6752.

Kheirbek MA, Klemenhagen KC, Sahay A, Hen R (2012a) Neurogenesis and generalization: a new approach to stratify and treat anxiety disorders. Nat Neurosci 15:1613-1620.

Kheirbek MA, Tannenholz L, Hen R (2012b) NR2B-dependent plasticity of adult-born granule cells is necessary for context discrimination. J Neurosci 32:8696-8702.

Kiraly DD, Lemtiri-Chlieh F, Levine ES, Mains RE, Eipper BA (2011) Kalirin binds the NR2B subunit of the NMDA receptor, altering its synaptic localization and function. J Neurosci 31:12554-12565.

Koleske AJ (2013) Molecular mechanisms of dendrite stability. Nat Rev Neurosci 14:536-550.

Kulkarni VA, Firestein BL (2012) The dendritic tree and brain disorders. Mol Cell Neurosci 50:10-20.

Lai KO, Ip NY (2013) Structural plasticity of dendritic spines: the underlying mechanisms and its dysregulation in brain disorders. Biochim Biophys Acta 1832:2257-2263.

Lai KO, Wong AS, Cheung MC, Xu P, Liang Z, Lok KC, Xie H, Palko ME, Yung WH, Tessarollo L, Cheung ZH, Ip NY (2012) TrkB phosphorylation by Cdk5 is required for activity-dependent structural plasticity and spatial memory. Nat Neurosci 15:1506-1515.

Lakso M, Pichel JG, Gorman JR, Sauer B, Okamoto Y, Lee E, Alt FW, Westphal H (1996) Efficient in vivo manipulation of mouse genomic sequences at the zygote stage. Proc Natl Acad Sci USA 93:5860-5865.

LeDoux JE (2000) Emotion circuits in the brain. Annu Rev Neurosci 23:155184.

Lefebvre JL, Sanes JR, Kay JN (2015) Development of dendritic form and function. Annu Rev Cell Dev Biol 31:741-777.

Lein ES, Zhao X, Gage FH (2004) Defining a molecular atlas of the hippocampus using DNA microarrays and high-throughput in situ hybridization. J Neurosci 24:3879-3889.

Lemtiri-Chlieh F, Zhao L, Kiraly DD, Eipper BA, Mains RE, Levine ES (2011) Kalirin-7 is necessary for normal NMDA receptor-dependent synaptic plasticity. BMC Neurosci 12:126.

Leuner B, Gould E (2010) Structural plasticity and hippocampal function. Annu Rev Psychol 61:111-140.

Lin YC, Yeckel MF, Koleske AJ (2013) Abl2/Arg controls dendritic spine and dendrite arbor stability via distinct cytoskeletal control pathways. J Neurosci 33:1846-1857.

Liu Y, Du S, Lv L, Lei B, Shi W, Tang Y, Wang L, Zhong Y (2016) Hippocampal activation of racl regulates the forgetting of object recognition memory. Curr Biol 26:2351-2357.
Lockstone HE, Harris LW, Swatton JE, Wayland MT, Holland AJ, Bahn S (2007) Gene expression profiling in the adult Down syndrome brain. Genomics 90:647-660.

Lopez-Rojas J, Kreutz MR (2016) Mature granule cells of the dentate gyrus: passive bystanders or principal performers in hippocampal function? Neurosci Biobehav Rev 64:167-174

Ma XM, Kiraly DD, Gaier ED, Wang Y, Kim EJ, Levine ES, Eipper BA, Mains RE (2008) Kalirin-7 is required for synaptic structure and function. J Neurosci 28:12368-12382.

Magliozzi R, Kim J, Low TY, Heck AJ, Guardavaccaro D (2014) Degradation of Tiam 1 by casein kinase 1 and the SCF $\beta$ TrCP ubiquitin ligase controls the duration of mTOR-S6K signaling. J Biol Chem 289:27400-27409.

Malliri A, van der Kammen RA, Clark K, van der Valk M, Michiels F, Collard JG (2002) Mice deficient in the Rac activator Tiam1 are resistant to Ras-induced skin tumours. Nature 417:867-871.

Martinez LA, Tejada-Simon MV (2011) Pharmacological inactivation of the small GTPase Racl impairs long-term plasticity in the mouse hippocampus. Neuropharmacology 61:305-312.

Masui T, Hashimoto R, Kusumi I, Suzuki K, Tanaka T, Nakagawa S, Suzuki T, Iwata N, Ozaki N, Kato T, Takeda M, Kunugi H, Koyama T (2008) A possible association between missense polymorphism of the breakpoint cluster region gene and lithium prophylaxis in bipolar disorder. Prog Neuropsychopharmacol Biol Psychiatry 32:204-208.

McAvoy KM, Scobie KN, Berger S, Russo C, Guo N, Decharatanachart P, Vega-Ramirez $H$, Miake-Lye S, Whalen $M$, Nelson M, Bergami M, Bartsch D, Hen R, Berninger B, Sahay A (2016) Modulating neuronal competition dynamics in the dentate gyrus to rejuvenate aging memory circuits. Neuron 91:1356-1373.

Mikhail FM, Descartes M, Piotrowski A, Andersson R, Diaz de Ståhl T, Komorowski J, Bruder CE, Dumanski JP, Carroll AJ (2007) A previously unrecognized microdeletion syndrome on chromosome 22 band q11.2 encompassing the BCR gene. Am J Med Genet A 143A:2178-2184.

Miller BR, Hen R (2015) The current state of the neurogenic theory of depression and anxiety. Curr Opin Neurobiol 30:51-58.

Miller MB, Yan Y, Eipper BA, Mains RE (2013) Neuronal Rho GEFs in synaptic physiology and behavior. Neuroscientist 19:255-273.

Ming GL, Song H (2011) Adult neurogenesis in the mammalian brain: significant answers and significant questions. Neuron 70:687-702.

Moresco EM, Donaldson S, Williamson A, Koleske AJ (2005) Integrin-mediated dendrite branch maintenance requires Abelson (Abl) family kinases. J Neurosci 25:6105-6118.

Mulherkar S, Firozi K, Huang W, Uddin MD, Grill RJ, Costa-Mattioli M, Robertson C, Tolias KF (2017) RhoA-ROCK inhibition reverses synaptic remodeling and motor and cognitive deficits caused by traumatic brain injury. Sci Rep 7:10689.

Narayanan AS, Reyes SB, Um K, McCarty JH, Tolias KF (2013) The RacGAP Bcr is a novel regulator of the Par complex that controls cell polarity. Mol Biol Cell 24:3857-3868

Newey SE, Velamoor V, Govek EE, Van Aelst L (2005) Rho GTPases, dendritic structure, and mental retardation. J Neurobiol 64:58-74.

Oh D, Han S, Seo J, Lee JR, Choi J, Groffen J, Kim K, Cho YS, Choi HS, Shin H, Woo J, Won H, Park SK, Kim SY, Jo J, Whitcomb DJ, Cho K, Kim H, Bae YC, Heisterkamp N, et al. (2010) Regulation of synaptic Rac1 activity, long-term potentiation maintenance, and learning and memory by BCR and ABR Rac GTPase-activating proteins. J Neurosci 30:14134-14144.

O’Toole TE, Bialkowska K, Li X, Fox JE (2011) Tiam1 is recruited to $\beta 1$ integrin complexes by $14-3-3 \zeta$ where it mediates integrin-induced Rac1 activation and motility. J Cell Physiol 226:2965-2978.

Park AR, Oh D, Lim SH, Choi J, Moon J, Yu DY, Park SG, Heisterkamp N, Kim E, Myung PK, Lee JR (2012) Regulation of dendritic arborization by BCR Rac1 GTPase-activating protein, a substrate of PTPRT. J Cell Sci 125:4518-4531.

Penzes P, Johnson RC, Sattler R, Zhang X, Huganir RL, Kambampati V, Mains RE, Eipper BA (2001) The neuronal Rho-GEF Kalirin-7 interacts with PDZ domain-containing proteins and regulates dendritic morphogenesis. Neuron 29:229-242.

Penzes P, Beeser A, Chernoff J, Schiller MR, Eipper BA, Mains RE, Huganir RL (2003) Rapid induction of dendritic spine morphogenesis by transsynaptic ephrinB-EphB receptor activation of the Rho-GEF kalirin. Neuron 37:263-274. 
Penzes P, Cahill ME, Jones KA, VanLeeuwen JE, Woolfrey KM (2011) Dendritic spine pathology in neuropsychiatric disorders. Nat Neurosci 14:285-293.

Qi H, Juo P, Masuda-Robens J, Caloca MJ, Zhou H, Stone N, Kazanietz MG, Chou MM (2001) Caspase-mediated cleavage of the TIAM1 guanine nucleotide exchange factor during apoptosis. Cell Growth Differ 12:603611.

Rahimi O, Claiborne BJ (2007) Morphological development and maturation of granule neuron dendrites in the rat dentate gyrus. In: The dentate gyrus: a comprehensive guide to structure, function, and clinical implications. Progress in brain research, pp 167-181. Amsterdam: Elsevier.

Ramakers GJ, Wolfer D, Rosenberger G, Kuchenbecker K, Kreienkamp HJ, Prange-Kiel J, Rune G, Richter K, Langnaese K, Masneuf S, Bösl MR, Fischer KD, Krugers HJ, Lipp HP, van Galen E, Kutsche K (2012) Dysregulation of Rho GTPases in the $\alpha$ Pix/Arhgef6 mouse model of Xlinked intellectual disability is paralleled by impaired structural and synaptic plasticity and cognitive deficits. Hum Mol Genet 21:268-286.

Ramirez-Amaya V, Marrone DF, Gage FH, Worley PF, Barnes CA (2006) Integration of new neurons into functional neural networks. J Neurosci 26:12237-12241

Rao S, Kay Y, Herring BE (2019) Tiam1 is critical for glutamatergic synapse structure and function in the hippocampus. J Neurosci 39:9306-9315.

Sahay A, Hen R (2007) Adult hippocampal neurogenesis in depression. Nat Neurosci 10:1110-1115.

Sahay A, Scobie KN, Hill AS, O'Carroll CM, Kheirbek MA, Burghardt NS, Fenton AA, Dranovsky A, Hen R (2011a) Increasing adult hippocampal neurogenesis is sufficient to improve pattern separation. Nature 472:466470.

Sahay A, Wilson DA, Hen R (2011b) Pattern separation: a common function for new neurons in hippocampus and olfactory bulb. Neuron 70:582588.

Sfakianos MK, Eisman A, Gourley SL, Bradley WD, Scheetz AJ, Settleman J, Taylor JR, Greer CA, Williamson A, Koleske AJ (2007) Inhibition of Rho via Arg and p190RhoGAP in the postnatal mouse hippocampus regulates dendritic spine maturation, synapse and dendrite stability, and behavior. J Neurosci 27:10982-10992.

Shin R, Kobayashi K, Hagihara H, Kogan JH, Miyake S, Tajinda K, Walton NM, Gross AK, Heusner CL, Chen Q, Tamura K, Miyakawa T, Matsumoto M (2013) The immature dentate gyrus represents a shared phenotype of mouse models of epilepsy and psychiatric disease. Bipolar Disord 15:405-421.

Sholl DA (1953) Dendritic organization in the neurons of the visual and motor cortices of the cat. J Anat 87:387-406.

Siddiqui A, Lacroix T, Stasko MR, Scott-McKean JJ, Costa AC, Gardiner KJ (2008) Molecular responses of the Ts65Dn and Ts1Cje mouse models of Down syndrome to MK-801. Genes Brain Behav 7:810-820.

Tamminga CA, Stan AD, Wagner AD (2010) The hippocampal formation in schizophrenia. Am J Psychiatry 167:1178-1193.

Tang LT, Diaz-Balzac CA, Rahman M, Ramirez-Suarez NJ, Salzberg Y, Lázaro-Peña MI, Bülow HE (2019) TIAM-1/GEF can shape somatosensory dendrites independently of its GEF activity by regulating F-actin localization. Elife 8:e38949.

Tolias KF, Bikoff JB, Burette A, Paradis S, Harrar D, Tavazoie S, Weinberg RJ, Greenberg ME (2005) The Rac1-GEF Tiam1 couples the NMDA receptor to the activity-dependent development of dendritic arbors and spines. Neuron 45:525-538.

Tolias KF, Bikoff JB, Kane CG, Tolias CS, Hu L, Greenberg ME (2007) The Rac1 guanine nucleotide exchange factor Tiam1 mediates EphB receptordependent dendritic spine development. Proc Natl Acad Sci USA 104:7265-7270.

Tolias KF, Duman JG, Um K (2011) Control of synapse development and plasticity by Rho GTPase regulatory proteins. Prog Neurobiol 94:133148.
Tu YK, Duman JG, Tolias KF (2018) The adhesion-GPCR BAI1 promotes excitatory synaptogenesis by coordinating bidirectional trans-synaptic signaling. J Neurosci 38:8388-8406.

Um K, Niu S, Duman JG, Cheng JX, Tu YK, Schwechter B, Liu F, Hiles L, Narayanan AS, Ash RT, Mulherkar S, Alpadi K, Smirnakis SM, Tolias KF (2014) Dynamic control of excitatory synapse development by a Rac1 GEF/GAP regulatory complex. Dev Cell 29:701-715.

Vacca M, Tripathi KP, Speranza L, Aiese Cigliano R, Scalabrì F, Marracino F, Madonna M, Sanseverino W, Perrone-Capano C, Guarracino MR, D'Esposito M (2016) Effects of Mecp2 loss of function in embryonic cortical neurons: a bioinformatics strategy to sort out non-neuronal cells variability from transcriptome profiling. BMC Bioinformatics 17 Suppl 2:14.

Vadodaria KC, Brakebusch C, Suter U, Jessberger S (2013) Stage-specific functions of the small Rho GTPases Cdc42 and Racl for adult hippocampal neurogenesis. J Neurosci 33:1179-1189.

von Bohlen Und Halbach O (2007) Immunohistological markers for staging neurogenesis in adult hippocampus. Cell Tissue Res 329:409-420.

Voncken JW, Baram TZ, Gonzales-Gomez II, van Schaick H, Shih JC, Chen K, Groffen J, Heisterkamp N (1998) Abnormal stress response and increased fighting behavior in mice lacking the bcr gene product. Int J Mol Med 2:577-583.

Wang S, Watanabe T, Matsuzawa K, Katsumi A, Kakeno M, Matsui T, Ye F, Sato K, Murase K, Sugiyama I, Kimura K, Mizoguchi A, Ginsberg MH, Collard JG, Kaibuchi K (2012) Tiam1 interaction with the PAR complex promotes talin-mediated Racl activation during polarized cell migration. J Cell Biol 199:331-345.

Warren MS, Bradley WD, Gourley SL, Lin YC, Simpson MA, Reichardt LF, Greer CA, Taylor JR, Koleske AJ (2012) Integrin $\beta 1$ signals through Arg to regulate postnatal dendritic arborization, synapse density, and behavior. J Neurosci 32:2824-2834.

Wehner JM, Radcliffe RA (2004) Cued and contextual fear conditioning in mice. Curr Protoc Neurosci Chapter 8:Unit 8.5C.

Wiskott L, Rasch MJ, Kempermann G (2006) A functional hypothesis for adult hippocampal neurogenesis: avoidance of catastrophic interference in the dentate gyrus. Hippocampus 16:329-343.

Wojtowicz JM, Kee N (2006) BrdU assay for neurogenesis in rodents. Nat Protoc 1:1399-1405.

Woodcock SA, Rooney C, Liontos M, Connolly Y, Zoumpourlis V, Whetton AD, Gorgoulis VG, Malliri A (2009) SRC-induced disassembly of adherens junctions requires localized phosphorylation and degradation of the rac activator Tiam1. Mol Cell 33:639-653.

Xie Z, Srivastava DP, Photowala H, Kai L, Cahill ME, Woolfrey KM, Shum CY, Surmeier DJ, Penzes P (2007) Kalirin-7 controls activity-dependent structural and functional plasticity of dendritic spines. Neuron 56:640656.

Xie Z, Cahill ME, Penzes P (2010) Kalirin loss results in cortical morphological alterations. Mol Cell Neurosci 43:81-89.

Xie Z, Cahill ME, Radulovic J, Wang J, Campbell SL, Miller CA, Sweatt JD, Penzes P (2011) Hippocampal phenotypes in kalirin-deficient mice. Mol Cell Neurosci 46:45-54.

Yoo S, Kim Y, Lee H, Park S, Park S (2012) A gene trap knockout of the Tiam-1 protein results in malformation of the early embryonic brain. Mol Cells 34:103-108.

Zhang H, Macara IG (2006) The polarity protein PAR-3 and TIAM1 cooperate in dendritic spine morphogenesis. Nat Cell Biol 8:227-237.

Zhao C, Teng EM, Summers RG, Ming GL, Gage FH (2006) Distinct morphological stages of dentate granule neuron maturation in the adult mouse hippocampus. J Neurosci 26:3-11.

Zhu G, Fan Z, Ding M, Mu L, Liang J, Ding Y, Fu Y, Huang B, Wu W (2014) DNA damage induces the accumulation of Tiam 1 by blocking $\beta$-TrCPdependent degradation. J Biol Chem 289:15482-15494. 